\title{
Adiponectin modulates ventral tegmental area dopamine neuron activity and anxiety-related behavior through AdipoR1
}

\author{
Fengjiao Sun ${ }^{1,2} \cdot$ Yun Lei $^{1,3} \cdot$ Jingjing You ${ }^{1} \cdot$ Chen $^{2 i^{2,3}} \cdot$ Linshan Sun $^{1} \cdot$ Jacob Garza ${ }^{1} \cdot$ Di Zhang $^{1} \cdot$ Ming Guo $^{2} \cdot$ \\ Phillip E. Scherer $\mathbb{D}^{4} \cdot$ Daniel Lodge $\mathbb{D}^{1} \cdot$ Xin-Yun Lu ${ }^{1,3}$
}

Received: 29 August 2017 / Revised: 2 May 2018 / Accepted: 11 May 2018 / Published online: 9 July 2018

(c) The Author(s) 2018. This article is published with open access

\begin{abstract}
Adiponectin, a metabolic hormone secreted by adipocytes, can cross the blood-brain barrier to act on neurons in different brain regions, including those involved in stress-related disorders. Here we show that dopamine neurons in the ventral tegmental area (VTA) express adiponectin receptor 1 (AdipoR1). Intra-VTA infusion of adiponectin or the adiponectin mimetic AdipoRon in wild-type mice decreases basal dopamine neuron population activity and firing rate and reverses the restraint stress-induced increase in dopamine neuron activity and anxiety behavior. Adiponectin haploinsufficiency leads to increased dopamine neuron firing and anxiety behavior under basal conditions. Ablation of AdipoR1 specifically from dopamine neurons enhances neuronal and anxiogenic responses to restraint stress. The effects of intra-VTA infusion of adiponectin on neuronal activity and behavior were abolished in mice lacking AdipoR1 in dopamine neurons. These observations indicate that adiponectin can directly modulate VTA dopamine neuron activity and anxiety behavior, and that AdipoR1 is required for adiponectin-induced inhibition of dopamine neurons and anxiolytic effects. These results strengthen the idea of adiponectin as a key biological factor that links metabolic syndrome and emotional disorders.
\end{abstract}

\section{Introduction}

The mesolimbic dopamine system, originating from dopamine neurons in the ventral tegmental area (VTA), is a key neural substrate for reward processing and emotional responses [1]. Dysfunction of this system has been linked to a number of psychiatric disorders including anxiety and

Electronic supplementary material The online version of this article (https://doi.org/10.1038/s41380-018-0102-9) contains supplementary material, which is available to authorized users.

$\triangle$ Xin-Yun Lu

xylu@augusta.edu

1 Department of Pharmacology, The University of Texas Health Science Center at San Antonio, San Antonio, TX, USA

2 Institute for Metabolic \& Neuropsychiatric Disorders, Binzhou Medical University Hospital, Shandong, China

3 Department of Neuroscience \& Regenerative Medicine, Medical College of Georgia, Augusta University, Augusta, GA, USA

4 Touchstone Diabetes Center, Department of Internal Medicine, University of Texas Southwestern Medical Center, Dallas, TX, USA depression [1-4]. While dopamine neurons are well known for their excitatory responses to rewards, it is becoming increasingly clear that the activity of dopamine neurons is also associated with aversive, stressful stimuli [3-8]. The activity of dopamine neurons is modulated not only by synaptic inputs but also by peripheral hormones [9-11]. The central and peripheral signals act in concert to determine the neuron's response to both rewarding and aversive/stressful stimuli.

Research suggests a bidirectional association between metabolic syndrome and anxiety $[12,13]$. These two conditions may share a common biological basis. It has been shown that midbrain dopamine neurons respond directly to a distinct set of metabolic hormones and relay signals from periphery to mesolimbic neural circuits [9-11, 14]. These studies have mainly focused on the functions of metabolic hormones in food rewards and energy metabolism. Given the critical role of the dopaminergic system in stress responses and emotional behavior [3-8], it is hypothesized that metabolic hormones may modulate stress and emotional processing via modulating dopamine neuron activity. Indeed, the adipocyte-derived hormone leptin was found to regulate VTA dopamine neuron firing and anxiety-related 
behavior $[10,14,15]$. However, whether similar effects extend to other adipocyte hormones is yet unknown.

Adiponectin, the most abundant circulating adipokine, is secreted exclusively by adipocytes $[16,17]$. In contrast to increased levels of leptin, adiponectin levels are reduced in individuals with obesity [18-22]. The anti-diabetic metabolic effects of adponectin have been well characterized $[23,24]$. Evidence suggests that adiponectin is able to cross the blood-brain barrier and act on specific neuronal populations through its receptors, AdipoR1 and AdipoR2 [2528]. These two receptor subtypes have distinct distribution patterns [29], different binding affinity for adiponectin and signaling preferences $[24,28,30]$. However, the precise physiological functions of AdipoR1 and AdipoR2 in the central nervous system remain to be elucidated. While AdipoR1 is widely expressed in the brain, AdipoR2 expression is restricted to only a few brain regions, including the hippocampus and hypothalamus [29]. We recently reported that AdipoR2 regulates neuronal excitability of hippocampal granule neurons and contextual fear in a mouse model of post-traumatic stress disorder [31]. In this study, we revealed that VTA neurons express AdipoR1 mRNA, suggesting that the VTA is a target for adiponectin action. We further investigated the effects of adiponectin in modulating VTA dopamine neuron firing activity and anxiety-like behavior under both basal and stress conditions. To test the hypothesis that AdipoR1 in dopamine neurons is necessary for the neuronal and behavioral effects of adiponectin, we generated mice lacking AdipoR1 in dopaminergic neurons. Our results indicate that adiponectin decreases the activity of VTA dopamine neurons and induces anxiolytic responses through direct activation of AdipoR1.

\section{Materials and methods}

\section{Animals}

C57BL/6J, DAT-IRES-cre and Ai14 mice were purchased from Jackson Laboratory (Bar Harbor, ME, USA). Heterozygous adiponectin gene knockout $\left(\mathrm{Adipo}^{+-}\right.$) mice were originally obtained from Dr. Philipp Scherer and maintained on a C57BL/6J genetic background [32]. To confirm the specificity of DAT-IRES-cre-mediated recombination in dopaminergic neurons, DAT-IRES-cre mice were crossed with the Ai14 tdTomato reporter line to obtain DAT-IREScre, Ai14 mice with tdTomato fluorescence in Creexpressing cells, which was used to determine the colocalization of tdTomato with a dopamine neuron marker. To generate conditional knockout mice lacking adiponectin receptor 1 (AdipoR1) in dopamine neurons, AdipoR $1^{\text {flox/flox }}$ mice, in which exon 2 is floxed [31], were crossed with
DAT-IRES-cre mice. The AdipoR $1^{\text {flox/+}}$, DAT-IRES-cre offspring were backcrossed with AdipoR $1^{\text {flox/flox }}$ mice to generate AdipoR $1^{\text {flox/flox }}$, DAT-IRES-cre (AdipoR $1^{\text {flox/flox } /}$ $\left.\mathrm{DAT}^{\mathrm{IREScre}}\right)$ and AdipoR1 ${ }^{\text {flox/flox }}$ littermate controls (Fig. 4a). The PCR primers used for genotyping were as follows: Adiponectin, forward-5'-GGACCCCTGAACTTG CTTCAC-3', reverse-5'-CACCCACAGTAATTCCATG GG-3', Neo-reverse-5'-GAATGGGCTGACCGCTTCCT CGTG-3' [32]; DAT ${ }^{\text {IREScre }}$, forward-5'-TGGCTGTTGG TGTAAAGTGG-3', reverse-5'-CCAAAAGACGGCAATATGGT-3', and AdipoR1 WT and flox, forward-5'CCCTGGGGATAGTTCTGGAT- ${ }^{\prime}$, reverse-5' ${ }^{\prime}$-TTACTCACTGGGCCCTGCTTG-3'. All mice were housed in groups of five per cage under a 12-h light/12-h dark cycle (lights on at 7:00 am) with ad libitum access to food and water. For the experiments, male mice at an age between 8 and 12 weeks were used and all animal procedures were approved by the Institutional Animal Care and Use Committee of University of Texas Health Science Center at San Antonio and Binzhou Medical University Hospital.

\section{RNA extraction and reverse transcriptase PCR}

Mice were decapitated and their brains were removed immediately. Coronal brain slices $(1 \mathrm{~mm})$ were cut using a mouse brain matrix/slicer (Braintree Sci., Inc., MA). The VTA area from each slice was then punched out using a well-polished tissue punch needle. VTA punches were homogenized and total RNA was extracted with a total RNA rapid extraction kit. HiScript II QRT SuperMix (Vazyme) was used to generate cDNA according to the following procedure: $300 \mathrm{ng}$ of total RNA and $4 \times$ $g$ DNA wiper mix were incubated at $42{ }^{\circ} \mathrm{C}$ for 2 min to remove genome contamination, then $5 \times$ HiScript II QRT SuperMix was added to the reaction mixture and incubated at $25^{\circ} \mathrm{C}$ for $10 \mathrm{~min}, 50^{\circ} \mathrm{C}$ for $30 \mathrm{~min}$, and $85^{\circ} \mathrm{C}$ for $5 \mathrm{~min}$. The resulting cDNA was used for real-time PCR detection using a StepOnePlus real-time PCR system (Applied Biosystems, Waltham, MA, USA). The primer sequences used to amplify each product were as follows: AdipoR1 exon 2: forward-5'-CCCGTATCCACCAGACACCGG-3'; reverse$5^{\prime}$-GGCAATGGGGCTCCTTCTGG-3' [31], mouse $\beta$ actin: forward-5'-GATCATTGCTCCTCCTGAGC-3', reverse-5'-ACTCCTGCTTGCTGATCCAC-3' [33]. The $\Delta \Delta C T$ method was used to obtain relative fold-change of target gene expression normalized by the housekeeping gene $\beta$-actin compared with control samples.

\section{Drugs}

Recombinant mouse full-length adiponectin (R\&D Systems, Minneapolis, MN, USA) was dissolved in artificial cerebrospinal fluid (aCSF, $137 \mathrm{mM} \mathrm{NaCl}, 2.7 \mathrm{mM} \mathrm{KCl}, 0.5$ 
$\mathrm{mM} \mathrm{MgCl} 2 \cdot 6 \mathrm{H}_{2} \mathrm{O}, 0.9 \mathrm{mM} \mathrm{CaCl}_{2} \cdot 2 \mathrm{H}_{2} \mathrm{O}, 1.5 \mathrm{mM} \mathrm{KH}_{2} \mathrm{PO}_{4}$, and $8.1 \mathrm{mM} \mathrm{Na}_{2} \mathrm{HPO}_{4}$ ). AdipoRon (AdipoGen, San Diego, CA, USA) was dissolved in dimethyl sulfoxide as a stock solution $(30 \mathrm{mM})$, which was diluted with aCSF for intraVTA injection. All mice were randomly assigned to different treatment groups.

\section{Cannula implantation and microinjection}

For intra-VTA microinjections, mice were anesthetized with an intramuscular injection of a cocktail containing ketamine $60 \mathrm{mg} / \mathrm{ml}$, acepromazine $1 \mathrm{mg} / \mathrm{ml}$, and xylazine $8 \mathrm{mg} / \mathrm{ml}$ $(0.1 \mathrm{ml} / \mathrm{kg}$, intramuscular) and mounted onto a stereotaxic frame. The skull surface was first coated with Kerr phosphoric acid gel etchant (Kerr USA). As described elsewhere $[15,29]$, after the bilateral guide cannula was inserted into the VTA (coordinates: $3.2 \mathrm{~mm}$ posterior to the bregma, 0.4 $\mathrm{mm}$ lateral to the midline, and $3.8 \mathrm{~mm}$ ventral to bregma), Kerr Prime was applied onto the skull and cannula surface. Then adhesive was brushed on top of the primer layer and light cured for $45 \mathrm{~s}$ with the VALO curing light (Ultradent Products). Finally, the dental cement was used to fill the area around the cannula and a dummy cannula was inserted into the guide cannula to maintain the cannula patency. Following surgery, animals were individually housed, handled daily and allowed to recover for 7 days. Microinjections were performed on conscious, unrestrained and freely moving mice in their home cages. On the experimental day, a 33-G stainless-steel injector connected to a 5$\mu \mathrm{l}$ syringe was inserted into the guide cannula and extended $1 \mathrm{~mm}$ beyond the tip. AdipoRon $(2 \mathrm{nmol} / \mu \mathrm{l})$ or vehicle was infused bilaterally in a volume of $0.5 \mu \mathrm{l}(0.25 \mu \mathrm{l}$ per side $)$ over $2.5 \mathrm{~min}$ at $30 \mathrm{~min}$ before anxiety-related behavioral tests. The injector tips were held in place for additional 5 min after the end of infusion to avoid backflow through the needle track.

For intra-VTA microinjection of AAV-DJ vectors containing the genes for Cre recombinase (AAV-Cre-GFP) or GFP alone (Vector Biolabs, Malvern, PA, USA), a total volume of $1.0 \mu \mathrm{l}$ AAV vectors $(0.5 \mu \mathrm{l}$ per side) were injected bilaterally into the VTA (coordinates: $3.2 \mathrm{~mm}$ posterior to the bregma, $0.4 \mathrm{~mm}$ lateral to the midline, and $4.8 \mathrm{~mm}$ ventral to bregma) of adult AdipoR $1^{\text {flox/flox }}$ mice after anesthetized, at a rate of $0.1 \mu \mathrm{l} / \mathrm{min}$ with a 33-gauge stainless-steel injector. Additional $5 \mathrm{~min}$ were allowed for diffusion and prevention of backflow. Anxiety-related behavioral tests or in vivo extracellular recording were conducted 21 days after AAV injection.

\section{Behavioral procedures}

All behavioral tests were performed on male mice in the late light phase. Animals were transferred to the testing room and habituated for $3-4 \mathrm{~h}$ before beginning experiments. Mice were exposed to $2 \mathrm{~h}$ restraint stress and then received intra-VTA infusion of AdipoRon $1.5 \mathrm{~h}$ after the cessation of restraint stress. Behavioral tests assessing anxiety behavior were performed $30 \mathrm{~min}$ after intra-VTA injection. The animals were tested in both the elevated plus maze and the light-dark exploration test with an inter-test interval of at least 3 days to minimize potential carryover effects between behavioral tests. The experimenters who scored the behaviors were blind to animals' genotypes and treatment conditions.

\section{Acute restraint stress}

Mice were transported to the procedure room in individual cages with some home cage bedding and habituated for $2 \mathrm{~h}$ without any disturbance. Restraint stress was performed in the animal's home cage by placing each mouse into a $50 \mathrm{ml}$ polystyrene tube with ventilation for $30 \mathrm{~min}$ or $2 \mathrm{~h}$. Control animals were briefly handled.

\section{Elevated plus maze test}

The elevated plus maze test is a validated and widely used anxiety paradigm in rodents, which is based on the natural conflict between the animal's drive to explore a new environment and the tendency to avoid a potentially dangerous area $[14,15,33-36]$. The maze consisted of four arms arranged around a central platform $\left(5 \times 5 \mathrm{~cm}^{2}\right)$ that allowed access to all of the arms. Mice were placed in the central platform facing the corner between a closed arm and an open arm, and allowed to explore the elevated plus maze for $5 \mathrm{~min}$. The test was recorded with a video camera mounted above the maze and connected to a computer. Behavioral performance was scored manually. The time spent on the open and closed arms and the numbers of entries made into each arm were measured. Entry was defined as all four paws entering one arm. The degree of anxiety was assessed by calculating the percentage of open arm time (time spent in the open arms/total time spent in all arms) and the percentage of open arm entries (entries into the open arms/total entries into all arms).

\section{Light-dark box test}

The light-dark test is based on a natural conflict of a mouse between the exploration of a novel environment and the innate aversion to brightly illuminated areas $[14,15,34$, 35]. The apparatus consists of a light $\left(27 \times 27 \times 30 \mathrm{~cm}^{3}\right)$ and a dark $\left(18 \times 27 \times 30 \mathrm{~cm}^{3}\right)$ compartment divided by a wall with a door between the two compartments. The light compartment was brightly illuminated with light intensity of 700 lux; and the dark compartment was black walled and 
covered at the top with black Plexiglas. Mice were placed individually in the center of the dark compartment facing away from the door. The latency for the mice to move to the light side and the time spent in the light compartment were recorded for $5 \mathrm{~min}$ with a video camera mounted above the light box. Entry to the light side was defined as all four paws entering the light compartment.

\section{Locomotor activity}

Locomotor activity was measured using the open field locomotor system (Omnitech Electronics Inc, Columbus, $\mathrm{OH})[14,15,33-35]$. The test apparatus consisted of an open field box $\left(40 \times 40 \times 30 \mathrm{~cm}^{3}\right)$ made of transparent acrylic surrounded by three sets of 16 photobeam arrays in the horizontal $x$ and $y$ axes as well as in the ventricle $z$ axis. Locomotor movements were determined by breaks in photobeams and converted into distance traveled with the Fusion Software. Total distance traveled for $30 \mathrm{~min}$ was analyzed using the Fusion Software (Omnitech Electronics Inc, Columbus, $\mathrm{OH}$ ).

\section{Electrophysiology}

Mice were anesthetized with $4 \%$ chloral hydrate $(400 \mathrm{mg} /$ $\mathrm{kg}$, intraperitoneally) and placed in a stereotaxic apparatus. Anesthesia was maintained by supplementary administration of chloral hydrate as required to suppress the limb compression withdrawal reflex. The core body temperature was sustained at $37^{\circ} \mathrm{C}$ via a thermostatically controlled heating pad. Extracellular recording electrodes were pulled from borosilicate glass capillaries and filled with $2 \mathrm{M} \mathrm{NaCl}$ containing 2\% Chicago sky blue dye (impedance 6-14 $\mathrm{M} \Omega$ ). The skull and dura were removed after an incision was made in the midline. Single-unit electrophysiological extracellular recording were performed as described previously [14]. Electrodes were lowered into the VTA (coordinates: 3.2 to $3.4 \mathrm{~mm}$ posterior to the bregma, 0.3 to $0.5 \mathrm{~mm}$ lateral to the midline, and 3.5 to $5.0 \mathrm{~mm}$ below the brain surface) using a micropositioner. Nine electrode tracks were made vertically throughout the VTA, each separated by $100 \mu \mathrm{m}$ and arranged in a grid pattern. Spontaneously active dopamine neurons were identified with open filter settings (low cutoff $=30 \mathrm{~Hz}$; high cutoff $=30 \mathrm{kHz}$ ) using established electrophysiological criteria $[37,38]$ and each neuron was recorded over a period of $3 \mathrm{~min}$. Three parameters of dopamine neuron activity were measured for each mouse: (1) population activity, the number of spontaneously active dopamine neurons recorded per track; (2) average spontaneous firing rate $(\mathrm{Hz})$; and (3) average percent burst firing, which is defined as the occurrence of two consecutive spikes with an interspike interval $<80 \mathrm{~ms}$, and the termination of a burst defined as two spikes with an interspike interval $>160 \mathrm{~ms}$ [38]. The average firing rate and the average percent burst firing were obtained by averaging the values of firing rate and percent of burst firing for all dopamine neurons recorded in each individual mouse. At the end of the experiments, mice were decapitated and their brains processed for histological verification of electrode tracks.

For the experiments involving intra-VTA injection, vehicle (aCSF, $0.5 \mu \mathrm{l})$, adiponectin $(0.15 \mu \mathrm{g}, 0.5 \mu \mathrm{l})$, or AdipoRon $(0.1$ or $1.0 \mathrm{nmol}, 0.5 \mu \mathrm{l})$ was infused into the VTA (coordinates: $3.3 \mathrm{~mm}$ posterior to the bregma, $0.4 \mathrm{~mm}$ lateral to the midline, and $4.2 \mathrm{~mm}$ ventral to bregma) with a 32 gauge Hamilton syringe at a rate of $0.5 \mu \mathrm{l} / 5 \mathrm{~min}$. Five additional minutes were allowed for diffusion and prevention of backflow through the needle track before the injector was withdrawn. Six electrode tracks ( 3.2 to $3.4 \mathrm{~mm}$ posterior to the bregma; 0.3 to $0.5 \mathrm{~mm}$ lateral to the midline; $3.5-5.0 \mathrm{~mm}$ below the brain surface) were made vertically throughout the VTA.

\section{In situ hybridization}

Radioactive in situ hybridization for detecting AdipoR1 and AdipoR2 gene expression were performed as previously described [29]. Briefly, brain sections were mounted on poly-lysine coated slides and sequentially fixed in $4 \%$ paraformaldehyde for $1 \mathrm{~h}$, rinsed in $2 \times \mathrm{SSC}(300 \mathrm{mM} \mathrm{NaCl}$, $30 \mathrm{mM} \mathrm{Na}$ citrate, $\mathrm{pH} 7.2$ ), acetylated in $0.1 \mathrm{M}$ triethanolamine ( $\mathrm{pH} 8.0$ ) with $0.25 \%$ (vol/vol) acetic anhydride for $10 \mathrm{~min}$ and dehydrated through a graded series of alcohol $(50-100 \%)$. The tissue sections were then incubated with $70 \mu \mathrm{l}$ of AdipoR1 or AdipoR2 cDNA probes labeled with $\mathrm{S}^{35}$-UTP and $\mathrm{S}^{35}$-CTP (PerkinElmer) at $55^{\circ} \mathrm{C}$ overnight, rinsed in $2 \times$ SSC and incubated in RNase A buffer (200 $\mathrm{mg} / \mathrm{ml}$ ) for $1 \mathrm{~h}$ at $37^{\circ} \mathrm{C}$ followed by a series of washes with increasing stringency $(2 \times, 1 \times, 0.5 \times \mathrm{SSC})$. Finally, the sections were placed in $0.1 \times \mathrm{SSC}$ at $70{ }^{\circ} \mathrm{C}$ for $1 \mathrm{~h}$, rinsed in distilled water, dehydrated in a graded series of alcohol, and exposed to X-ray film.

To examine whether AdipoR1 mRNA is colocalized with dopamine neurons in the VTA, we performed double in situ hybridization. cRNA probes complementary to either the mouse AdipoR1 mRNA or the mouse tyrosine hydroxylase (TH) mRNA were labeled with digoxigenin-11-UTP (for the AdipoR1 probe) or fluorescein-12-UTP (for the TH probe) using standard transcription methods. The brain sections were hybridized with a 1:1 mixture of the labeled probes at $55^{\circ} \mathrm{C}$ overnight and subsequently rinsed in $2 \times$ SSC, treated with RNase A $(200 \mu \mathrm{g} / \mathrm{ml})$ for $1 \mathrm{~h}$ at $37^{\circ} \mathrm{C}$, and washed in $2 \times, 1 \times, 0.5 \times$, and $0.1 \times \operatorname{SSC}$ (for 5 min each), with a final rinse in $0.1 \times \mathrm{SSC}$ at $65^{\circ} \mathrm{C}$ for $1 \mathrm{~h}$. After the tissue was cooled to room temperature, it was processed for immunohistochemical staining for visualization of 

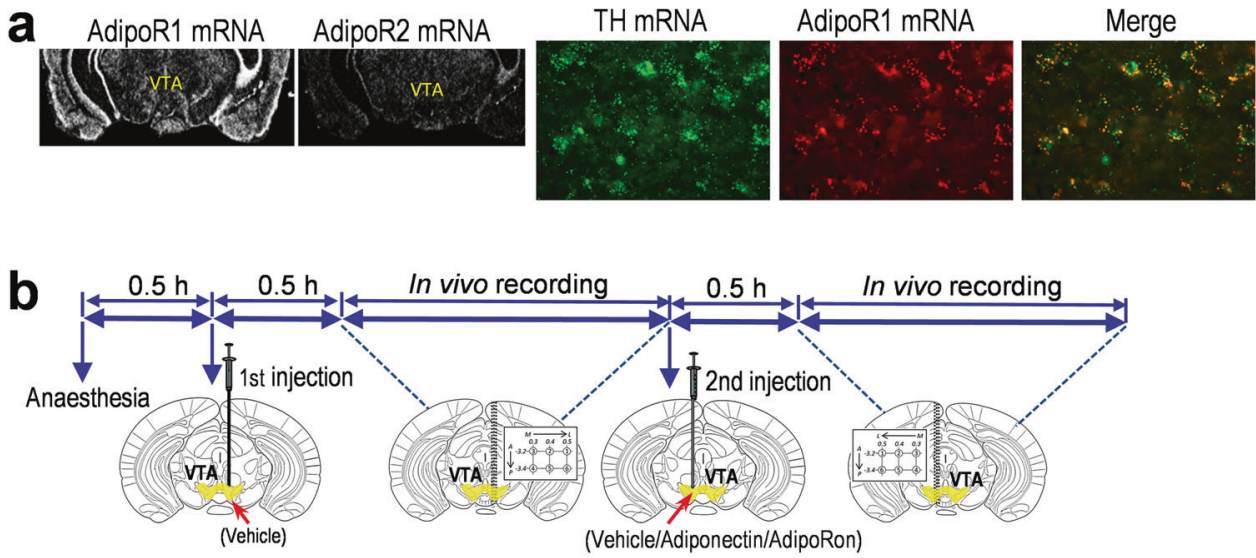

C Intra-VTA microinjection: Vehicle/Vehicle

1st Vehicle
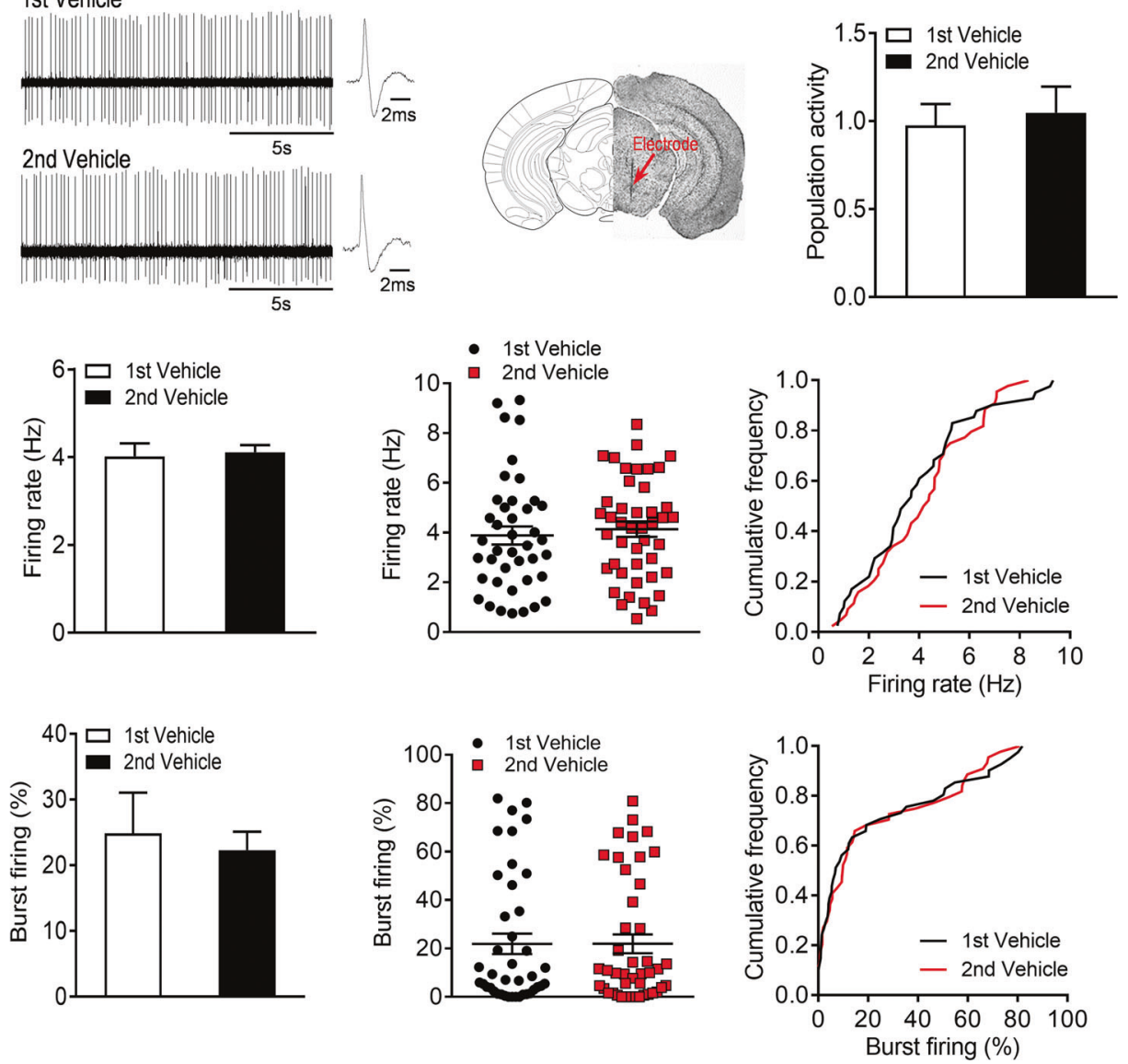

digoxigenin-11-labeled TH probe using the TSA Plus Fluorescence System kit (PerkinElmer). To accomplish this, brain sections were treated with $2 \%$ hydrogen peroxide in $0.05 \mathrm{M}$ PBS for $30 \mathrm{~min}$. The sections were then placed in a blocking solution (PerkinElmer) for $1 \mathrm{~h}$ followed by incubation with anti-fluorescence-HRP (Roche) overnight in a humidified chamber. The next day, the sections were rinsed in PBS and incubated with the fluorescein tyramide amplification reagent (PerkinElmer) for $15 \mathrm{~min}$ to reveal $\mathrm{TH}$ staining. For visualization of AdipoR1 mRNA, the sections were incubated with $2 \%$ hydrogen peroxide in $0.05 \mathrm{M}$ PBS for $30 \mathrm{~min}$, then rinsed in PBS followed by incubation with a sheep anti-digoxygenin antibody (Roche) in the blocking solution overnight. The sections were then rinsed and incubated for $1 \mathrm{~h}$ with anti-sheep-HRP secondary antibody in a humidified chamber. The sections were rinsed in PBS followed by incubation with the cyanine 3 tyramide amplification reagent (PerkinElmer) for $15 \mathrm{~min}$. After 
Fig. 1 Effects of intra-VTA infusion of adiponectin and AdipoRon on dopamine neuron activity. (a) In situ hybridization showing expression patterns of AdipoR1 and AdipoR2 mRNA in the VTA (left) and colocalization of AdipoR1 and tyrosine hydroxylase (TH) mRNA (right). (b) Schematic procedure of in vivo extracellular recording of dopamine neurons in the VTA. (c) Effects of intra-VTA vehicle injection. Top-left, representative extracellular voltage traces from identified dopamine neurons in the VTA; top-center, representative image demonstrating the electrode track through the VTA; top-right, number of spontaneously active dopamine neurons per track in the VTA. Middle-left, firing rate; middle-center, scatter plot distribution; middle-right, cumulative frequency distribution. Bottom-left, percent burst firing; bottom-center, scatter plot distribution; bottom-right, cumulative frequency distribution. 1st vehicle: $n=7$ mice; 2 nd vehicle: $n=7$ mice. (d) Effects of intra-VTA adiponectin injection. Topleft, representative extracellular voltage traces from VTA dopamine neurons; top-center, representative image demonstrating the electrode track through the VTA; top-right, number of spontaneously active dopamine neurons per track in the VTA. Middle-left, firing rate; middle-center, scatter plot distribution; middle-right, cumulative frequency distribution. Bottom-left, percent burst firing; bottom-center, scatter plot distribution; bottom-right, cumulative frequency distribution. $* P<0.05, * * P<0.01$ compare with the vehicle-treated control group. Vehicle: $n=7$ mice; adiponectin: $n=7$ mice. (e) Effects of intra-VTA AdipoRon injection. Top-left, representative extracellular voltage traces from VTA dopamine neurons; top-center, representative image demonstrating the electrode track through the VTA; top-right, number of spontaneously active dopamine neurons per track in the VTA. Middle-left, firing rate; middle-center, scatter plot distribution; middle-right, cumulative frequency distribution. Bottom-left, percent burst firing; bottom-center, scatter plot distribution; bottom-right, cumulative frequency distribution. $* P<0.05$, ${ }^{*} * P<0.01$ compare with the vehicle-treated group. Vehicle 1: $n=8$ mice; AdipoRon $0.1 \mathrm{nmol}$ : $n=8$ mice; Vehicle 2: $n=8$ mice; AdipoRon 1.0 nmol: $n=8$ mice. VTA ventral tegmental area

rinsing, the slides were coverslipped immediately with the ProLong Gold antifade reagent (Invitrogen). For evaluation of the colocalization of AdipoR1 mRNA and TH mRNA, six consecutive sections through the VTA were analyzed. Signal specificity was ensured either by hybridization with sense-strand probes or pretreatment of brain sections with RNase A $\left(200 \mu \mathrm{g} / \mathrm{ml}\right.$ at $37^{\circ} \mathrm{C}$ for $\left.1 \mathrm{~h}\right)$.

\section{Immunofluorescence histochemistry}

DAT-IRES-cre, Ai14 mice were perfused transcardially with $0.1 \mathrm{M}$ phosphate-buffered saline (PBS) (pH 7.4) followed by $4 \%$ paraformaldehyde (PFA) in $0.1 \mathrm{M}$ PBS. The brains were removed and postfixed in $4 \%$ PFA at $4{ }^{\circ} \mathrm{C}$ for at least $24 \mathrm{~h}$, and then transferred to $30 \%$ sucrose in PBS. Brains were sectioned to $40 \mu \mathrm{m}$ coronal sections on a cryostat and stored in a cryoprotectant solution (30\% sucrose, $30 \%$ ethylene glycol, $1 \%$ polyvinyl pyrolidone, $0.05 \mathrm{M}$ sodium phosphate buffer). Brain sections were blocked for $1 \mathrm{~h}$ in a blocking buffer (1\% BSA, 3\% donkey serum and $0.3 \%$ Triton $\mathrm{X}-100$ in PBS) and incubated with Rabbit anti-TH primary antibody (1:2000, \#AB52, Millipore, Temecula, CA) overnight at $4{ }^{\circ} \mathrm{C}$ and then Alexa
Fluor 488 donkey anti-Rabbit $\operatorname{IgG}$ antibody (1:400, A21206, Invitrogen, Carlsbad, CA) for $1 \mathrm{~h}$. Sections were mounted on coated slides and coverslipped using ProLong Gold antifade reagent. Expression of tdTomato and TH fluorescent staining and their colocolization were observed using Olympus fluorescence microscope.

\section{Western blot assay}

Mice were decapitated rapidly, and trunk blood was collected in tubes containing $20 \mu \mathrm{l}$ of $0.5 \%$ ethylenediaminetetraacetic acid disodium and centrifuged at $1000 \times g$ for 10 min. The supernatant plasma was collected and stored at $-20{ }^{\circ} \mathrm{C}$. Western blotting for the measurement of adiponectin levels was performed as describe elsewhere [29, 33]. In brief, plasma samples were mixed with $5 x$ sodium dodecyl sulfate-polyacrylamide gel electrophoresis loading dye (Beyotime Biotechnology, Shanghai, China) and denatured by boiling at $100{ }^{\circ} \mathrm{C}$ for $10 \mathrm{~min}$. Denatured proteins ( $5 \mu$ tenfold diluted plasma sample) were separated on an sodium dodecyl sulfate-polyacrylamide gel electrophoresis and transferred to polyvinylidene fluoride membrane. The membrane was blocked in Tris-buffered saline containing $1 \%$ dried milk and $0.1 \%$ Tween 20 , and then incubated with anti-adiponectin antibody (Cat. \#AF1119, 1:1000, R\&D systems, Minneapolis, MN, USA) overnight at $4{ }^{\circ} \mathrm{C}$. After washing, the membrane was incubated with a secondary antibody, donkey anti-goat IgG (Cat. \#92632214; 1:5000, LI-COR Biosciences, Lincoln, NE, USA). Signals were visualized and quantitatively analyzed.

\section{Histology}

After the completion of behavioral tests, mice were killed by decapitation. Brains were sectioned at $40 \mu \mathrm{m}$ and the placement of the cannula was verified. Animals with misplaced cannula were excluded from data analysis.

\section{Statistical analysis}

The Shapiro-Wilk test was used to determine whether the data set was normally distributed. Statistical significance was assessed by two-tailed, unpaired or paired Student's $t$ test and one-way analysis of variance (ANOVA) for data with normal distribution and equal variance, or by the Mann-Whitney test, Wilcoxon signed-rank test, and Kruskal-Wallis test for data not following normal distribution or with unequal variance. Significant effects in the analysis of variances were followed up with Holm-Sidak (for parametric analysis) or Dunn's (for non-parametric analysis) post-hoc tests. Results were considered significantly different when $P<0.05$. All data were presented as mean \pm standard error (s.e.m.). 
d Intra-VTA microinjection: Vehicle/Adiponectin
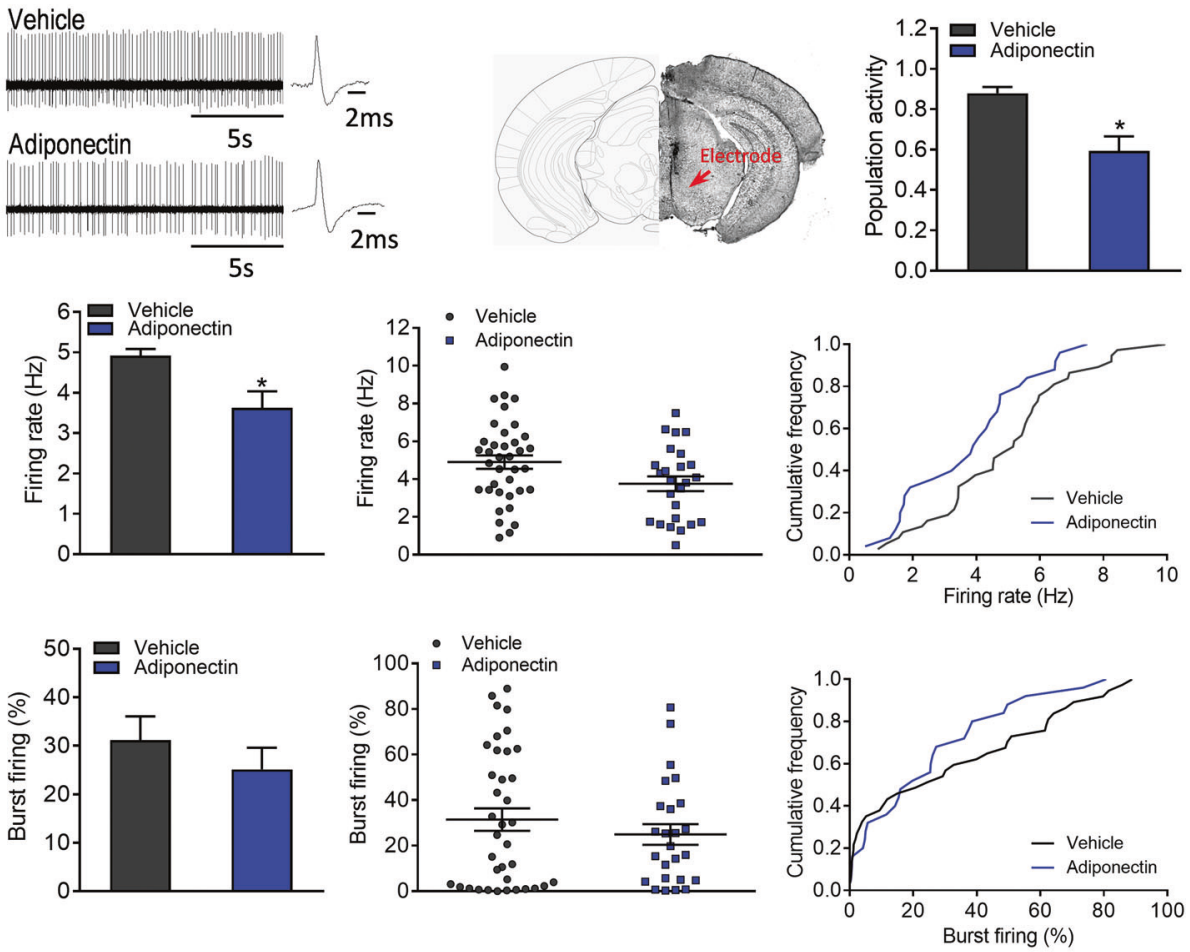

e Intra-VTA microinjection: Vehicle/AdipoRon

Vehicle
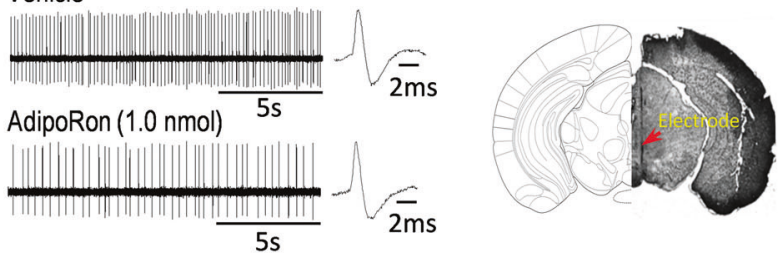

$\square$ Vehicle1

밀oRon $0.1 \mathrm{nmol}$

$\left.{ }^{6}\right\rceil$ Vehicle2 $1.0 \mathrm{nmol}$
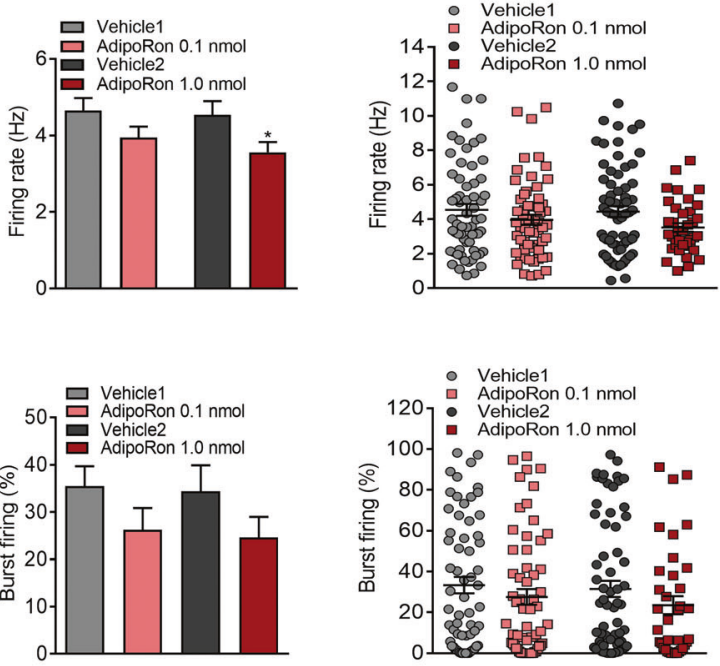
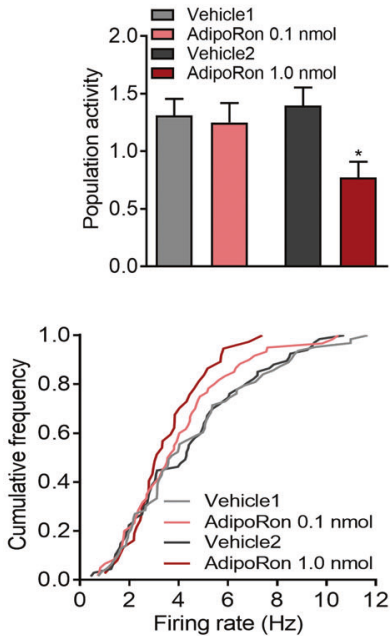

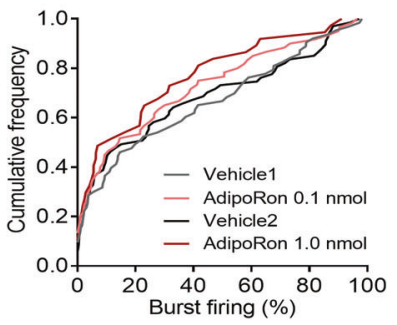

Fig. 1 (Continued) 


\section{Results}

\section{Expression of AdipoR1 in VTA dopamine neurons}

To determine whether AdipoR1 and AdipoR2 are expressed in VTA dopamine neurons, we first performed in situ hybridization with radioactive cRNA probes to examine the expression patterns of AdipoR1 and AdipoR2 mRNA in the VTA. We found that AdipoR1 mRNA was abundant in the VTA, whereas AdipoR2 mRNA was almost undetectable in this region (Fig. 1a). Furthermore, double-labeling in situ hybridization with non-radioactive fluorescein-labeled and digoxigenin-labeled cRNA probes revealed that the vast majority of dopamine neurons labeled with TH in the VTA expressed AdipoR1 mRNA (Fig. 1a). This finding provides the anatomical basis for a possible modulation of dopamine neuron activity by adiponectin/AdipoR1 signaling.

\section{Inhibition of VTA dopamine neuron firing by local infusion of adiponectin and AdipoRon}

Given the expression of AdipoR1 in VTA dopamine neurons, we tested whether local intra-VTA infusion of fulllength adiponectin modulates the firing properties of dopamine neurons. The spontaneous firing activity of putative VTA dopamine neurons in anesthetized wild-type mice was recorded using the in vivo extracellular single-unit recording technique. In order to reduce error variance due to individual differences, we used a within-subjects design, in which dopamine neurons in the VTA were recorded after two separate, sequential infusions in the two sides of the VTA of each mouse (Fig. 1b). First, we tested whether the temporal sequence of two intra-VTA infusion recordings could be a potential confounding variable. We compared spontaneous dopamine neuron firing activity recorded following the first vs. second intra-VTA vehicle (aCSF) infusion. As shown in Figure 1c, there were no significant differences in dopamine neuron population activity, the average firing rate and average percentage of burst firing between the first and second intra-VTA vehicle infusion $(0.5 \mu \mathrm{l} / \mathrm{side}$; number of spontaneously active dopamine neurons per electrode track: 1st Vehicle, $0.98 \pm 0.12$ neurons/track, total 41 neurons from seven mice; 2nd Vehicle, $1.05 \pm 0.15$ neurons/track, total 44 neurons from seven mice; $t_{(6)}=0.609, P=0.565$; average firing rate: 1 st Vehicle, $4.02 \pm 0.30 \mathrm{~Hz}$; 2nd Vehicle, $4.11 \pm 0.16 \mathrm{~Hz}$; $t_{(6)}=$ $0.321, P=0.759$; percentage of burst firing: 1st Vehicle, $24.84 \pm 6.22 \%, 37$ neurons; 2 nd Vehicle, $22.32 \pm 2.82 \%$; 39 neurons; Wilcoxon signed-rank test, $P=0.938$ ).

Following intra-VTA infusion of adiponectin $(0.15 \mu \mathrm{g}$ in $0.5 \mu \mathrm{l}$ ), the number of spontaneously active dopamine neurons per electrode track was significantly decreased in comparison with the vehicle aCSF) treated group (Vehicle:
$0.88 \pm 0.03$ neurons/track, total 37 neurons from seven mice; Adiponectin: $0.60 \pm 0.07$ neurons/track, total 25 neurons from seven mice; Wilcoxon signed-rank test, $P=$ 0.031; Fig. 1d). The average firing rate of VTA dopamine neurons was also reduced by intra-VTA infusion of adiponectin (Vehicle: $4.92 \pm 0.16 \mathrm{~Hz}$; Adiponectin: $3.63 \pm 0.40$ $\mathrm{Hz} ; t_{(6)}=2.865, \mathrm{P}=0.029$; Fig. 1d). However, and the average percentage of burst firing was not significantly different between adiponectin and vehicle injections (Vehicle: $31.20 \pm 4.88 \%$, 36 neurons; Adiponectin: $25.13 \pm$ $4.47 \%, 25$ neurons; $t_{(6)}=0.992, P=0.359$; Fig. 1d). These results suggest that adiponectin in the VTA inhibits dopamine neuron firing activity.

To further confirm these findings, we examined the effects of AdipoRon, a small-molecule adiponectin mimetic that binds both AdipoR1 and AdipoR2 with high affinity, on dopamine neuron firing patterns [39]. Similar to the observations with adiponectin, intra-VTA infusion of AdipoRon reduced the number of spontaneously active dopamine neurons per track (Vehicle1: $1.31 \pm 0.14$ neurons/ track, total 63 neurons from eight mice; AdipoRon 0.1 nmol: $1.25 \pm 0.17$ neurons/track, total 60 neurons from eight mice; $t_{(7)}=0.263, P=0.800$. Vehicle2: $1.40 \pm 0.16$ neurons/track, total 67 neurons from eight mice; AdipoRon 1.0 nmol: $0.77 \pm 0.14$ neurons/track, total 37 neurons from eight mice; Wilcoxon signed-rank test, $P=0.023$ ) and average firing rate (Vehicle1: $4.65 \pm 0.33 \mathrm{~Hz}$; AdipoRon $0.1 \mathrm{nmol}$ : $3.95 \pm 0.28 \mathrm{~Hz} ; t_{(7)}=2.129, P=0.071$. Vehicle2: $4.54 \pm$ $0.36 \mathrm{~Hz}$; AdipoRon $1.0 \mathrm{nmol}: 3.56 \pm 0.27 \mathrm{~Hz} ; t_{(7)}=3.362$, $P=0.012$ ) in a dose-dependent manner (Fig. 1e). The percentage of burst firing was not significantly altered by AdipoRon (Vehicle1: $35.5 \pm 4.22 \%$, 57 neurons; AdipoRon $0.1 \mathrm{nmol}: 26.26 \pm 4.60 \%, \quad 52$ neurons; $t_{(7)}=1.652, P=$ 0.143. Vehicle2: $34.4 \pm 5.46 \%, 63$ neurons; AdipoRon 1.0 nmol: $24.62 \pm 4.36 \%, 33$ neurons; $t_{(7)}=1.373, P=0.212$. Figure 1e). These results suggest that activation of AdipoR, possibly the AdipoR1 subtype, in the VTA exerts inhibitory effects on dopamine neuron firing.

\section{Intra-VTA infusion of AdipoRon reverses acute restraint stress-induced increase in VTA dopamine neuron firing}

Previous reports have demonstrated that VTA dopamine neurons are excited during acute restraint stress in rats [5, 7]. We examined whether a similar effect can be induced by restraint stress in mice and whether such effect can be reversed by AdipoRon. Wild-type mice were exposed to $2 \mathrm{~h}$ of restraint stress or brief handling followed by intra-VTA infusion of AdipoRon prior to in vivo extracellular recordings of VTA dopamine neurons (Fig. 2a1). We found that restraint stress increased the number of spontaneously active dopamine neurons in the VTA, and this effect was 
Fig. 2 Effect of AdipoRon on acute restraint stress-induced effects on VTA dopamine neuron activity and anxiogeniclike response. (a1) Schematic timeline of acute restraint stress, intra-VTA microinjection and in vivo extracellular recordings. (a2) Left, representative extracellular voltage traces from dopamine neurons in the VTA; right, representative image demonstrating the electrode track through the VTA. (a3) Number of spontaneously active dopamine neurons per track through the VTA. (a4) Firing rate: bar graph (left), scatter plot (middle) and cumulative frequency distribution (right). (a5) Proportion of burst firing: bar graph (left), scatter plot (middle) and cumulative frequency distribution (right). Control + vehicle: $n=7$ mice, 53 neurons; restraint stress + vehicle: $n=7$ mice, 76 neurons; restraint stress + AdipoRon: $n$ $=7$ mice, 48 neurons. (b1) Schematic timeline of acute restraint and behavioral testing procedures. (b2) Elevated plus maze test. Left, percentage of open/total arm time. Right, percentage of open/total arm entries. Control + vehicle: $n=$ 10 mice; restraint stress + vehicle: $n=10$ mice; restraint stress + AdipoRon: $n=10$ mice. (b3) Light-dark box test. Left, latency to enter the light side. Right, time spent in the light compartment. Control + vehicle: $n=8$ mice; restraint stress + vehicle: $n=6$ mice; restraint stress + AdipoRon: $n$ $=8$ mice. (b4) Representative image (upper) and schematic illustration of injection sites in the VTA (lower). $* P<0.05$ compared with the non-stressed, vehicle-treated group. ${ }^{\#} P<0.05$, ${ }^{\# \#} P<0.01$ compared with the stressed, vehicle-treated group a1

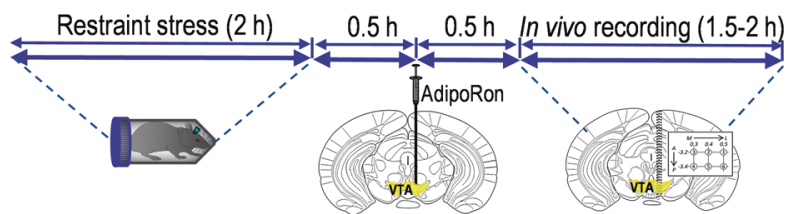

a2

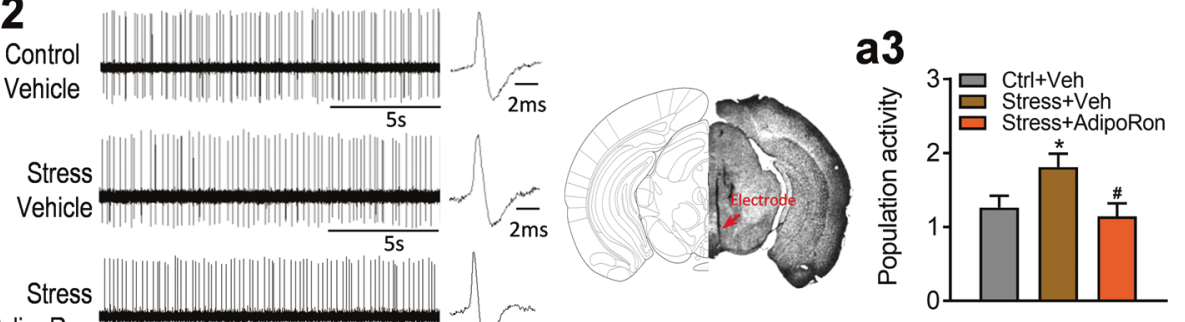

a4
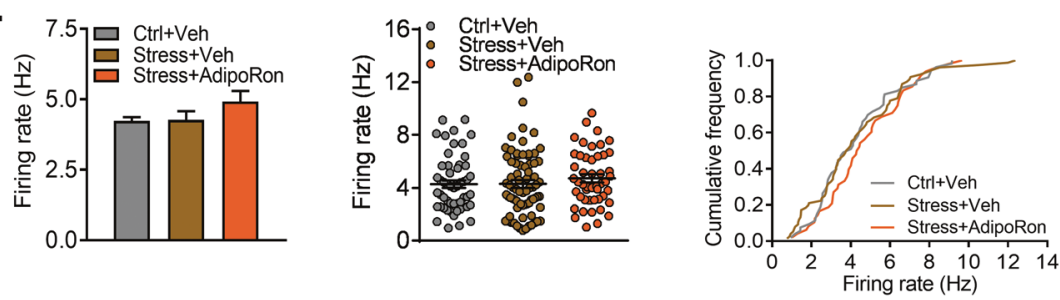

a5
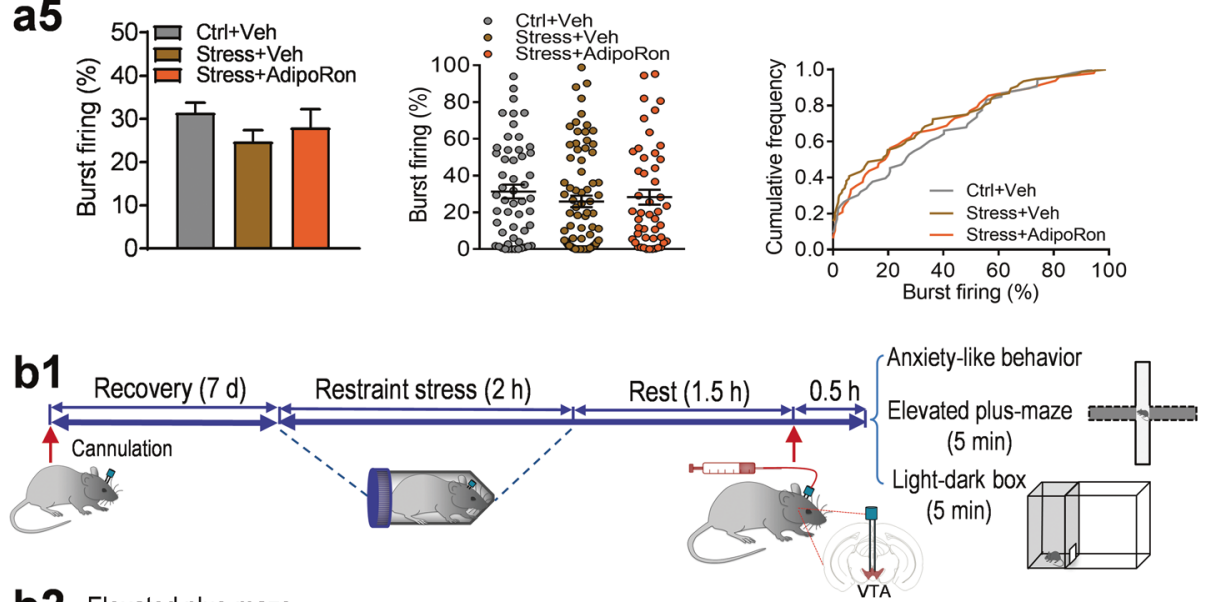

b2 Elevated plus-maze
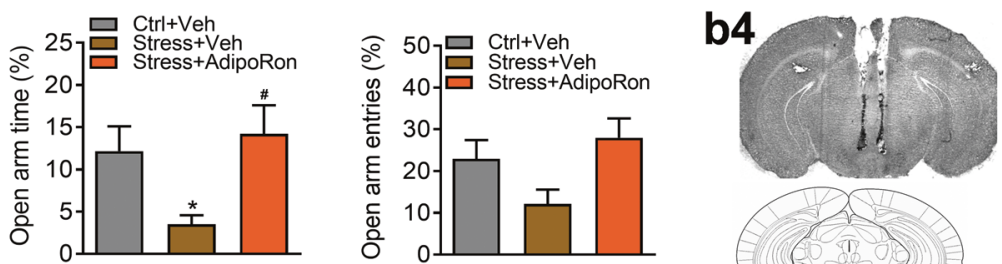

b3 Light-dark box
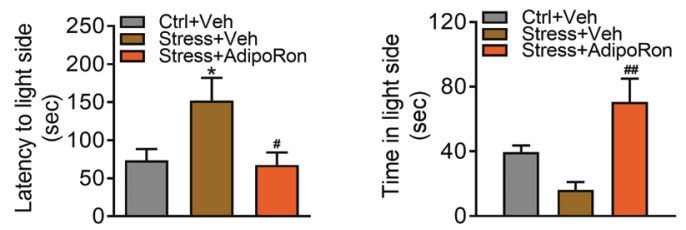

4. Bregma $-3.16 \mathrm{~mm}$

es Bregma $-3.28 \mathrm{~mm}$

B. Bregma $-3.40 \mathrm{~mm}$
- Bregma $-3.52 \mathrm{~mm}$ significantly reversed by intra-VTA infusion of AdipoRon (control + vehicle: $1.26 \pm 0.16$ neurons/track, total 53 neurons from seven mice; restraint stress + vehicle: $1.81 \pm 0.18$ neurons/track, total 76 neurons from seven mice; restraint stress + AdipoRon: $1.14 \pm 0.18$ neurons/track, total 48 neurons from seven mice; one-way ANOVA, $F_{(2,18)}=$ 
a

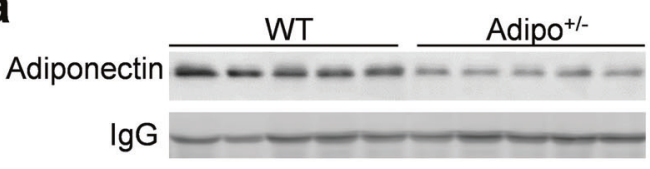

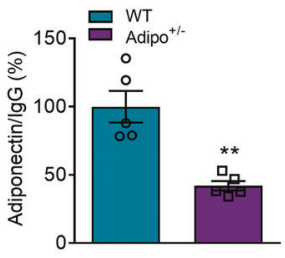

b3 Light-dark box
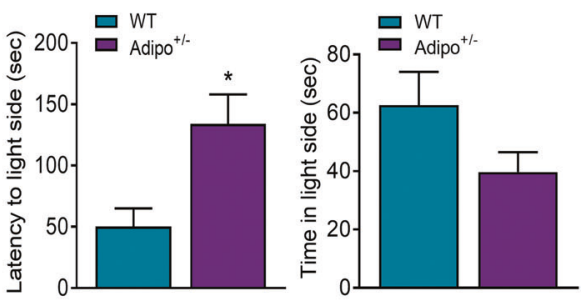

\section{In vivo DA neuron firing}
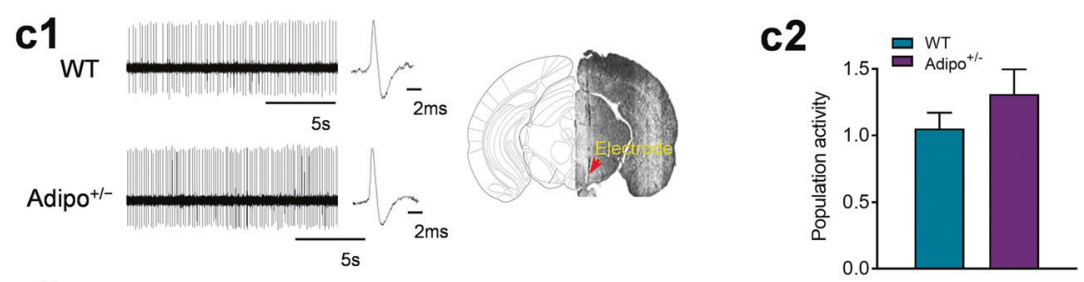

c3
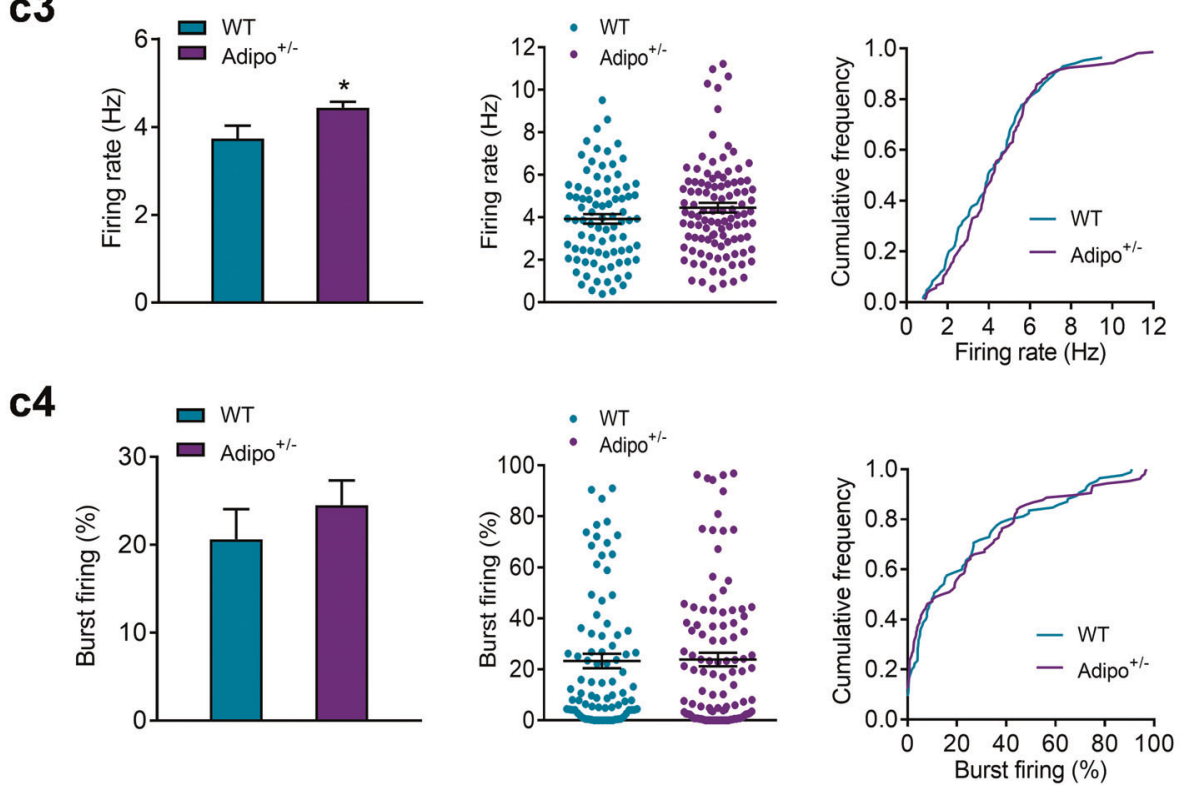

Fig. 3 Effects of adiponectin insufficiency on anxiety-like behavior and VTA dopamine neuron activity. (a) Plasma adiponectin levels. $n$ $=5$ mice per group. (b) Behavioral tests. (b1) Locomotor activity. WT: $n=11$ mice; Adipo ${ }^{+/-}: n=10$ mice. (b2) Elevated plus maze test. Left, percentage of open/total arm time. Right, percentage of open/total arm entries. WT: $n=11$ mice; Adipo ${ }^{+/-}: n=9$ mice. (b3) Light-dark box test. Left, latency to enter the light side; right, time spent in the light compartment. WT: $n=11$ mice; Adipo ${ }^{+-}: n=21$ mice. (c1) Left, representative extracellular voltage traces from VTA dopamine neurons; right, representative image demonstrating the electrode track through the VTA. (c2) Number of spontaneously active dopamine neurons per track. (c3) Firing rate: bar graph (left), scatter plot (middle) and cumulative frequency distribution (right). (c4) Percentage of burst firing: bar graph (left), scatter plot (middle) and cumulative frequency distribution (right). WT: $n=9$ mice; Adipo ${ }^{+-}: n=9$ mice. $* P<0.05, * * P<0.01$ compared with wild-type littermate control (WT) mice 
4.295, $P=0.030$; Fig. 2a3). There were no significant differences in average firing rate (control + vehicle: $4.23 \pm$ $0.13 \mathrm{~Hz}$; restraint stress + vehicle: $4.27 \pm 0.31 \mathrm{~Hz}$; restraint stress + AdipoRon: $4.92 \pm 0.37 \mathrm{~Hz}$; one-way ANOVA, F $(2,18)=1.789, P=0.196$; Fig. 2a4 $)$ and percentage of burst firing (control + vehicle: $31.40 \pm 2.34 \%, 48$ neurons; restraint stress + vehicle: $24.71 \pm 2.65 \%, 64$ neurons; restraint stress + AdipoRon: $27.99 \pm 4.26 \%, 45$ neurons; one-way ANOVA, $\mathrm{F}_{(2,18)}=1.099, P=0.355$; Fig. 2a5) between two treatment groups.

\section{Adiponectin reverses acute restraint stress-induced anxiogenic responses}

Changes in VTA dopamine neuron activity have been associated with stress-induced anxiety [2, 7, 40, 41]. We first asked whether central administration of adiponectin affects anxiety behavior. Wild-type mice received intracerebroventricular (ICV) injection of adiponectin $(0.1,0.3 \mu \mathrm{g})$ $30 \mathrm{~min}$ before the elevated plus maze and light/dark box tests to assess anxiety-like behavior. We found that adiponectin treatment significantly increased the percentage of open/total arm entries $\left(\mathrm{F}_{(2,39)}=4.081, P=0.025\right)$ and induced a trend toward an increase in the percentage of open/total arm time (Kruskal-Wallis test, $P=0.119$ ) in the elevated plus maze test (Supplementary Fig. 1a). Also, an increase in the time spent in the light compartment during the light/dark box test was observed after ICV infusion of adiponectin $\left(\mathrm{F}_{(2,21)}=4.857, \quad P=0.019 ; \quad\right.$ Supplementary Fig. 1b). These data suggest a central anxiolytic action of adiponectin. We next examined whether restraint stressinduced anxiogenic behavior can be attenuated by intraVTA infusion of AdipoRon. Mice were first exposed to $2 \mathrm{~h}$ of restraint stress, then AdipoRon was infused into the VTA bilaterally $30 \mathrm{~min}$ before testing (Fig. 2b1). The elevated plus maze and light/dark box tests were performed at $2 \mathrm{~h}$ after cessation of restraint stress. Restraint stress significantly reduced the percentage of open/total arm time, whereas intra-VTA injection of AdipoRon in stressed mice increased the percentage of both open/total arm time and entries in the elevated plus maze test (open/total arm time: $\mathrm{F}_{(2,27)}=4.534, \quad P=0.020 ; \quad$ open/total arm entries: Kruskal-Wallis test, $P=0.073$; Fig. 2b2). In the light/dark box test, restraint stress increased the latency to the light side and decreased the time spent in the light compartment; these effects were reversed by intra-VTA infusion of AdipoRon (latency to the light side: Kruskal-Wallis test, $P=$ 0.014 ; time in the light side: $\mathrm{F}_{(2,19)}=7.531, P=0.004$; Fig. 2b3).These results indicate that activation of adiponectin receptors in the VTA is sufficient to reverse stressinduced anxiety, in parallel with its inhibition of spontaneous firing activity of dopamine neurons.

\section{Adiponectin insufficiency increases VTA dopamine neuron firing activity and induces anxiogenic behavior}

Next, we investigated whether reduced endogenous adiponectin levels in mice affect VTA dopamine neuron firing activity and anxiety-related behavior. As shown previously $[29,32,42]$, adiponectin-haploinsufficient $\left(\right.$ Adipo $^{+/}$) mice have $42 \%$ of normal plasma adiponectin levels (wildtype: $100 \pm 11.62 \%, n=5$ mice; Adipo $^{+-}: 42.00 \pm 3.48 \%$, $n=5$ mice; $t_{(8)}=4.780, P=0.001$; Fig. 3a), representing a model with endogenous adiponectin insufficiency. Adipo ${ }^{+/-}$ mice showed normal locomotor activity in the open field test $\left(t_{(19)}=1.079, P=0.294\right.$; Fig. 3b1), decreased percentage of open/total arm time and entries in the elevated plus maze test (open/total arm time: Mann-Whitney test, $P=$ 0.015; open/total arm entries: Mann-Whitney test, $P=$ 0.015; Fig. 3b2) and increased latency to the light side in the light/dark box test (latency to the light side: Mann-Whitney test, $P=0.027$; time in the light side: Mann-Whitney test, $P=0.130$; Fig. 3b3), indicating an anxiogenic phenotype.

To determine if increased anxiety in $\mathrm{Adipo}^{+/-}$mice is correlated with changes in VTA dopamine neuron firing activity, we performed in vivo extracellular recordings of VTA dopamine neurons from Adipo $^{+/}$mice and their wildtype littermate controls. Adipo ${ }^{+/-}$mice exhibited normal population activity of dopamine neurons (WT: $1.05 \pm 0.12$ neurons/track, total 85 neurons from nine mice; Adipo $^{+/}$: $1.31 \pm 0.19$ neurons/track, total 106 neurons from nine mice; $t_{(16)}=1.171, P=0.259$; Fig. 3c2) and percentage of burst firing (WT: $20.63 \pm 3.43 \%, 78$ neurons; Adipo $^{+-}$: $24.52 \pm 2.83 \%, \quad 93$ neurons; $t_{(16)=0.875,} \quad P=0.394$; Fig. 3c4), but a significant increase in the firing rate (WT: $3.73 \pm 0.29 \mathrm{~Hz} ;$ Adipo $^{+-}: 4.44 \pm 0.13 \mathrm{~Hz} ; t_{(16)}=2.181, P=$ 0.044; Fig. 3c3).

\section{Deletion of AdipoR1 in the VTA increases anxiety- like behavior}

To determine if AdipoR1 is involved in mediating anxietylike behavior, AdipoR $1^{\text {flox/flox }}$ mice received bilateral infusion of AAV-Cre-GFP or AAV-GFP into the VTA and were subjected to the elevated plus maze and light/dark box tests 3 weeks after AAV injection. Mice injected with AAV-Cre-GFP in the VTA displayed a decreased tendency in the percentage of open arm time (Mann-Whitney test, $P=0.072)$ and the percentage of open arm entries $\left(t_{(12)}=\right.$ $1.943, P=0.076$ ) (Supplementary Fig. 2). In the light-dark box test, mice injected with AAV-Cre-GFP explored the light compartment to a lesser extent than mice injected with AAV-GFP (latency to enter the light side: Mann-Whitney test, $P=0.336$; time spent in the light side: $t_{(13)}=2.169$, 

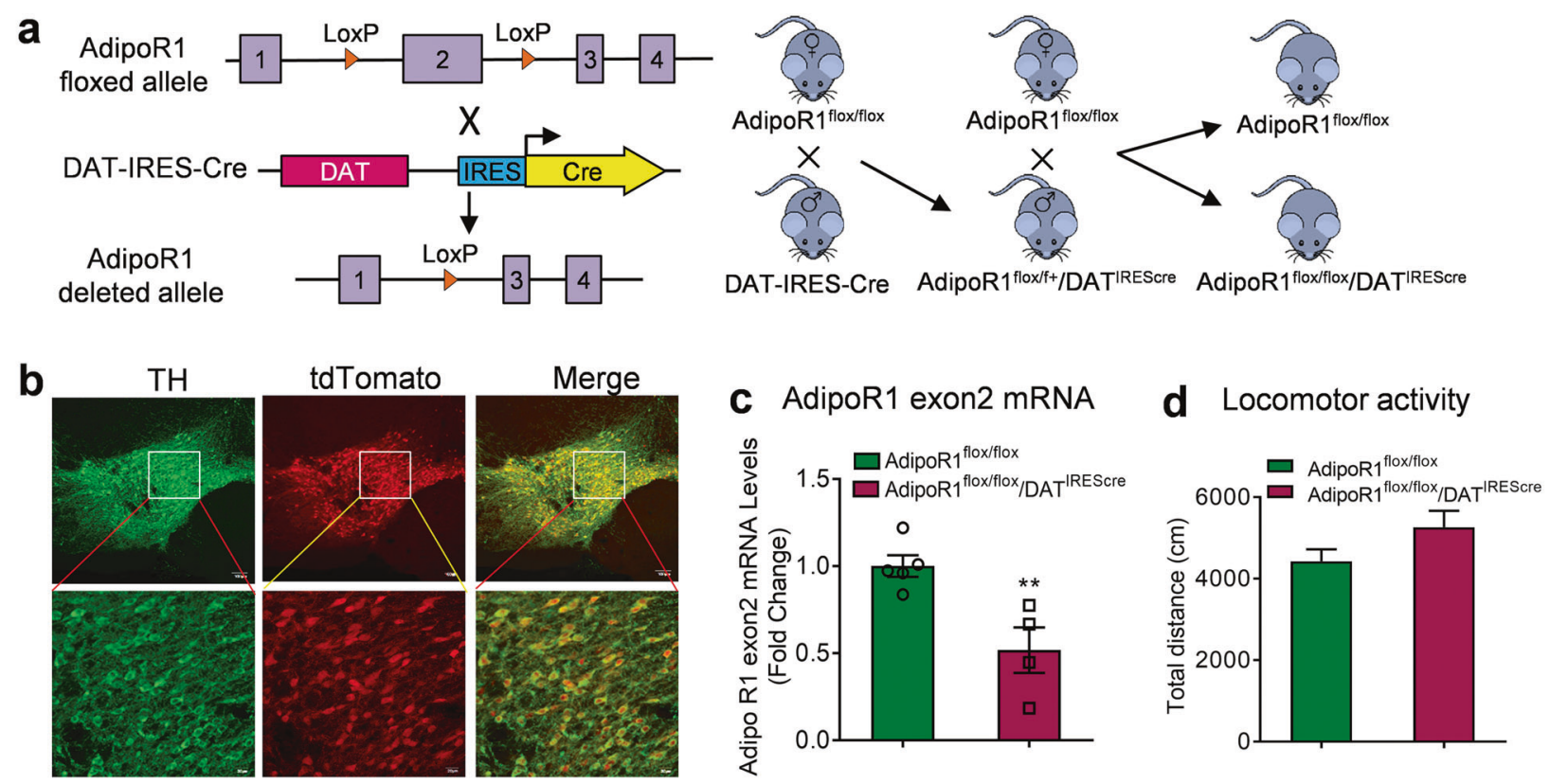

\section{e Basal conditions}

Elevated plus-maze
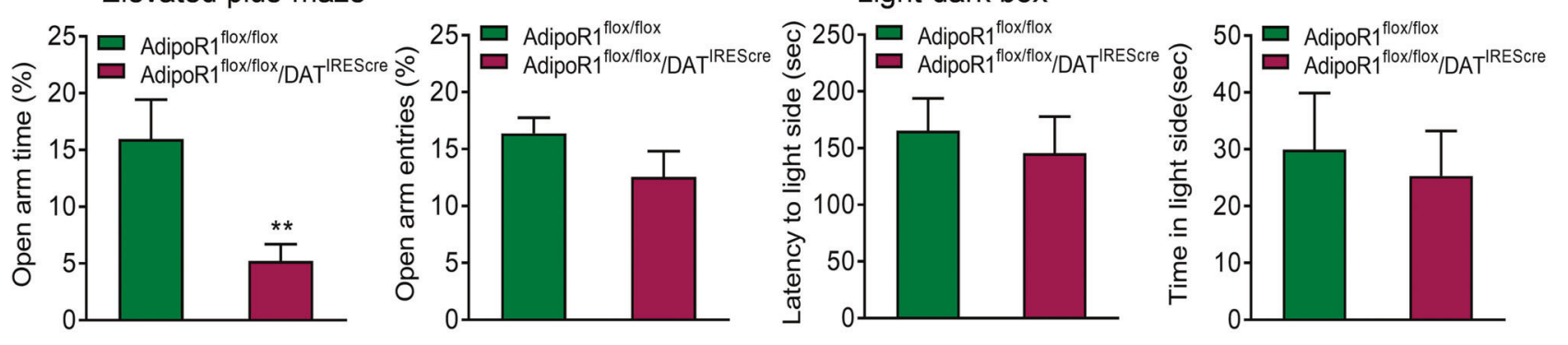

f Restraint stress (30 min)

Elevated plus-maze
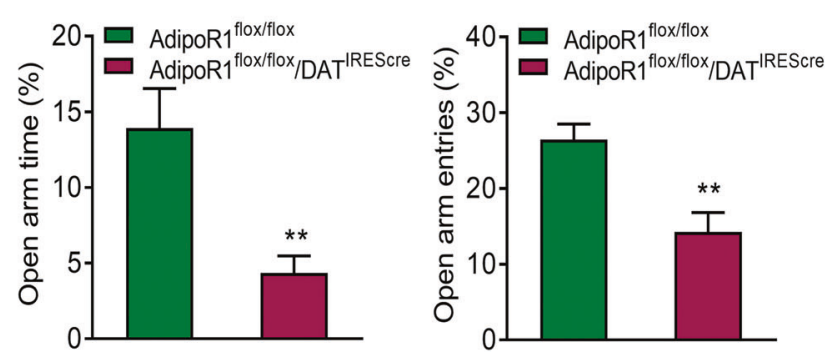

$P=0.049) \quad$ (Supplementary Fig. 2). These observations suggest that AdipoR1 in the VTA may play an important role in mediating anxiety-related behaviors.

\section{Deletion of AdipoR1 specifically in dopamine neurons results in anxiogenic behavior}

To determine the physiological relevance of adiponectin/ AdipoR1 signaling in dopamine neurons to anxiety-related

\section{Light-dark box}

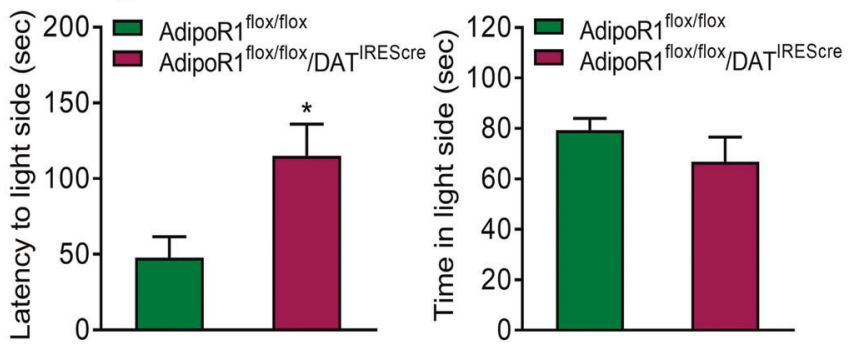

behavior, we generated mice lacking AdipoR1 specifically in dopamine neurons using the Cre-loxP system. The DATIRES-cre mice have Cre recombinase expression directed to dopaminergic neurons, without disrupting endogenous dopamine transporter expression [43]. The specificity of DAT-IRES-cre-mediated recombination was confirmed by crossing DAT-IRES-cre mice with a tdTomato reporter line (Ai14). tdTomato fluorescence was exclusively colocalized with the dopamine neuron marker TH (Fig. 4b). To delete 
Fig. 4 Effects of AdipoR1 deletion in dopamine neurons on anxietylike behavior and VTA dopamine neuron activity. (a) Schematic diagram of generation of mice with AdipoR1 deletion in dopamine neurons. (b) Colocalization of DAT-IRES-cre (tdTomato fluorescence, red) and tyrosine hydroxylase (TH, green). (c) Real-time PCR analysis showing the Cre-mediated deletion of exon 2 of AdipoR1 in the VTA of AdipoR $1^{\text {flox/flox }} / \mathrm{DAT} \mathrm{T}^{\mathrm{IREScre}}$ mice. AdipoR $1^{\text {flox/flox }}: n=5$ mice; AdipoR $1^{\text {flox/flox }} / \mathrm{DAT}^{\text {IREScre }}: n=4$ mice. (d) Locomotor activity. AdipoR1 ${ }^{\text {flox/flox }}: n=14$ mice; AdipoR $1^{\text {flox/flox }} / \mathrm{DAT}^{\mathrm{IRES} c r e}: n=12$ mice. (e) Behavioral tests for anxiety under basal non-stress conditions. Left and middle-left, elevated plus maze test. AdipoR $1^{\text {flox/flox}}: n=14$ mice; AdipoR $1^{\text {flox/flox }} / \mathrm{DAT}^{\mathrm{IREScre}}: n=11$ mice. Middle-right and right, light-dark box test. AdipoR $1^{\text {flox/flox}}: n=14$ mice; AdipoR $1^{\text {flox/flox/ }}$ $\mathrm{DAT}^{\mathrm{IRES} c r e}: n=12$ mice. (f) Behavioral tests for anxiety after 30-min restraint stress. Left and middle-left, elevated plus maze test. AdipoR $1^{\text {flox/flox }}: n=9$ mice; AdipoR $1^{\text {flox/flox}} / \mathrm{DAT}{ }^{\mathrm{IREScre}}: n=7$ mice. Middle-right and right, light-dark box test. AdipoR $1^{\text {flox/flox }}: n=8$ mice; AdipoR $1^{\text {flox/flox} / D A T ~}{ }^{\text {IREScre. }} n=7$ mice. (g) Firing activities of VTA dopamine neurons under basal non-stress conditions. (g1) Upper, representative extracellular voltage traces from dopamine neurons in the VTA; lower, representative image demonstrating the electrode track through the VTA. (g2) Number of spontaneously active dopamine neurons per track. (g3) Left, firing rate; middle, scatter plot distribution; right, cumulative frequency distribution. (g4) Left, proportion of burst firing; middle, scatter plot distribution; right, cumulative frequency distribution. AdipoR $1^{\text {flox/flox }}: n=7$ mice, AdipoR $1^{\text {flox/ }}$ flox/DAT ${ }^{\text {IREScre }}: n=7$ mice. (h) Firing activities of VTA dopamine neurons after 30-min restraint stress. (h1) Upper, representative extracellular voltage traces from dopamine neurons in the VTA; lower, representative image demonstrating the electrode track through the VTA. (h2) Number of spontaneously active dopamine neurons per track. (h3) Left, firing rate; middle, scatter plot distribution; right, cumulative frequency distribution. (h4) Left, proportion of burst firing; middle, scatter plot distribution; right, cumulative frequency distribu-

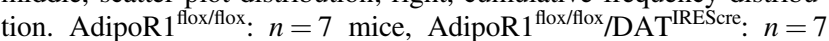
mice. $* P<0.05, * * P<0.01$ compared with AdipoR $1^{\text {flox/llox }}$ littermate controls

AdipoR1 from dopamine neurons, DAT-IRES-cre mice were crossed with AdipoR $1^{\text {flox/flox }}$ mice that possess loxP sites flanking exon 2 of the AdipoR 1 gene [31]. The deletion of exon 2 causes a frameshift that results in null mutation of AdipoR1 [31]. Cre-mediated excision of AdipoR1 exon 2 in the VTA of AdipoR $1^{\text {flox/flox }} / \mathrm{DAT}{ }^{\text {IREScre }}$ mice was confirmed by real-time PCR showing reduced exon 2 mRNA levels $\left(t_{(7)}=3.585, P=0.009\right.$; Fig. 4c). The microdissections of the VTA unavoidably contained non-dopamine neurons and adjacent tissue, which may account for the residual exon 2 expression.

AdipoR $1^{\text {flox/flox }} / \mathrm{DAT} \mathrm{T}^{\text {IREScre }}$ mice showed normal locomotor activity in the open field test compared with littermate AdipoR $1^{\text {flox/flox }}$ controls $\left(t_{(24)}=1.710, \quad P=0.100\right.$; Fig. 4d). Under basal (non-stress) conditions, AdipoR $1^{\text {flox/ }}$ flox $/ D A T^{\text {IREScre }}$ mice displayed a decrease in the percentage of open/total arm time (Mann-Whitney test, $P=0.009$ ), but no significant change in the percentage of open/total arm entries (Mann-Whitney test, $P=0.442$ ) in the elevated plus maze test (Fig. 4e). In the light/dark box test, AdipoR $1^{\text {flox/ }}$ flox $/ \mathrm{DAT} \mathrm{TREScre}^{\mathrm{IRE}}$ mice showed normal latency to the light side $\left(t_{(24)}=0.465, P=0.646\right)$ and the time spent in the light compartment (Mann-Whitney test, $P=0.733$ ) (Fig. $4 \mathrm{e}$ ). We further determined if deletion of AdipoR1 from dopamine neurons increases the sensitivity to stress. AdipoR $1^{\text {flox/ }}$

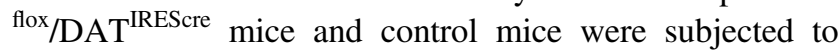
short-term $(30 \mathrm{~min})$ restraint stress before behavioral testing. AdipoR $1^{\text {flox/flox }} / \mathrm{DAT} \mathrm{T}^{\mathrm{IRES} \text { cre }}$ mice exhibited enhanced anxiety-like behavior in response to restraint stress as indicated by reduced percentages of open/total arm time and entries in the elevated plus maze test (open/total arm time: Mann-Whitney test, $P=0.005$; open/total arm entries: $t_{(13)}$ $=3.738, P=0.003$ ) and increased latency to the light side in the light/dark box test (latency to the light side: $t_{(12)}=$ 2.787, $P=0.016$; time in the light side: $t_{(12)}=1.262, P=$ 0.231) compared to AdipoR $1^{\text {flox/flox }}$ control mice (Fig. 4f). These data demonstrate that AdipoR1 signaling in dopamine neurons is critical for the modulation of anxiety-like behavior in response to stress.

To determine whether the insertion of loxP sites affects anxiety behavior, AdipoR $1^{\text {flox/flox }}$ mice and wild-type mice were subjected to the elevated plus maze and light/dark box tests. No differences were observed in these two tests between AdipoR $1^{\text {flox/flox }}$ mice and wild-type mice (Elevated plus maze: open/total arm time: $t_{(11)}=0.180, P=0.860$; open/total arm entries: $t_{(11)}=0.810, P=0.435$; Light $/$ dark box: latency to enter the light side: $t_{(13)}=0.526, P=0.608$; time spent in the light side: $t_{(13)}=0.490, P=0.632$ ) (Supplementary Fig. 3).

\section{Targeted deletion of AdipoR1 in dopamine neurons potentiates VTA dopamine neuron response to stress}

To understand the role of adiponectin/AdipoR1 signaling in modulating VTA dopamine neuronal activity, we examined the firing properties of VTA dopamine neurons in AdipoR $1^{\text {flox/flox }} / \mathrm{DAT}{ }^{\mathrm{IRES} \text { cre }}$ mice and AdipoR $1^{\text {flox/flox }}$ littermate controls. In vivo recordings within the VTA revealed no difference in the number of spontaneously active dopamine neurons, firing rate and percentage of burst firing between the two genotypes (number of active neurons: AdipoR $1^{\text {flox/ }}$ flox: $0.81 \pm 0.11$ neurons/track; AdipoR $1^{\text {flox/flox }} / \mathrm{DAT} \mathrm{T}^{\mathrm{IREScre}}$ : $0.76 \pm 0.12$ neurons/track; Mann-Whitney test, $P=0.679$; firing rate: AdipoR $1^{\text {flox/flox }}: 4.17 \pm 0.35 \mathrm{~Hz}$; AdipoR $1^{\text {flox/flox }}$ DAT $^{\text {IREScre }}: 3.85 \pm 0.34 \mathrm{~Hz} ; t_{(12)}=0.655, P=0.525$; percent burst firing: AdipoR1 $1^{\text {flox/flox: }} 35.22 \pm 6.84 \%$, 47 neurons; AdipoR $1^{\text {flox/flox } / D A T}{ }^{\text {IREScre: }} \quad 28.30 \pm 3.76 \%, \quad 43$ neurons; Mann-Whitney test, $P=0.456$; AdipoR1 $1^{\text {flox/flox }}$, 51 neurons from seven mice; AdipoR $1^{\text {flox/flox }} / \mathrm{DAT} \mathrm{T}^{\text {IREScre }} 48$ neurons from seven mice; Fig. $4 \mathrm{~g}$ ). Following exposure to $30 \mathrm{~min}$ of restraint stress, AdipoR $1^{\text {flox/flox }} / \mathrm{DAT} \mathrm{T}^{\mathrm{IRES} \text { cre }}$ mice exhibited significantly higher firing rate of VTA dopamine neurons compared to AdipoR $1^{\text {flox/flox }}$ littermate controls 


\section{g Basal conditions}
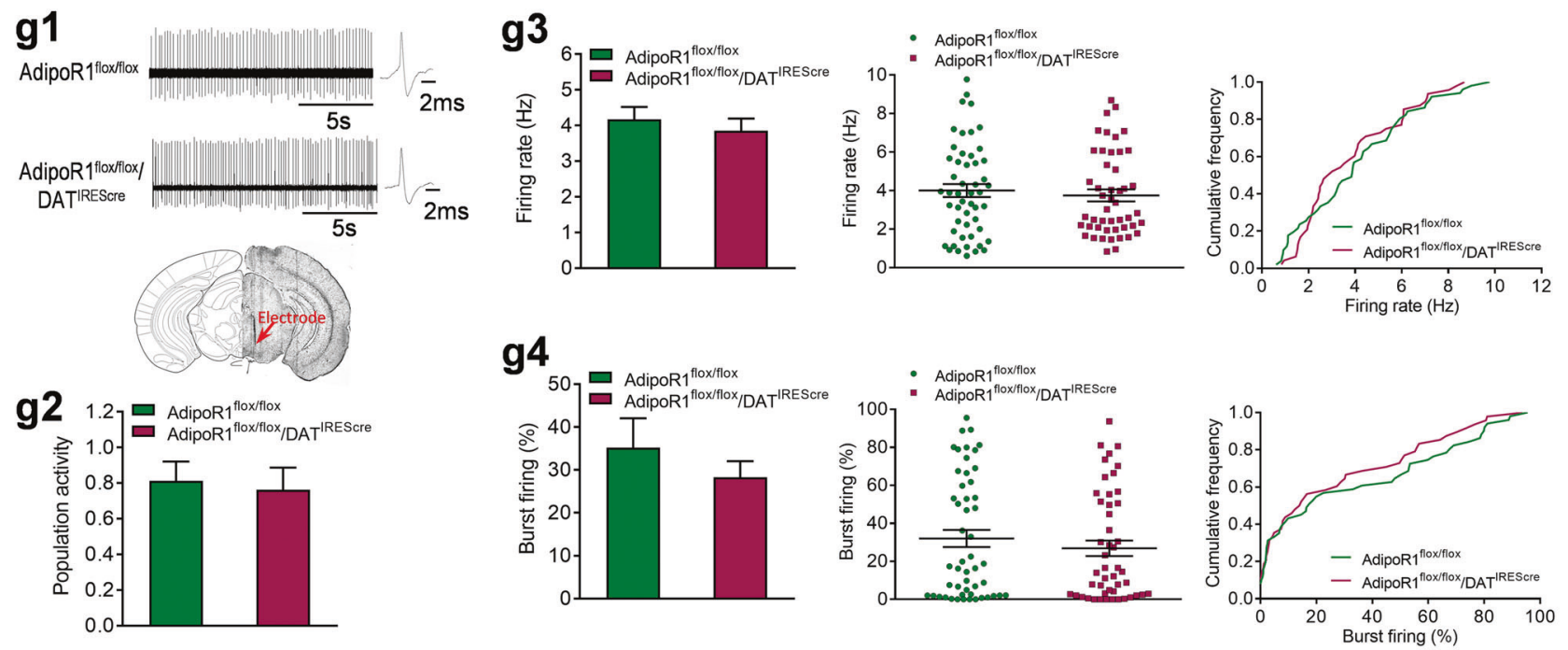

\section{h Restraint stress (30 min)}
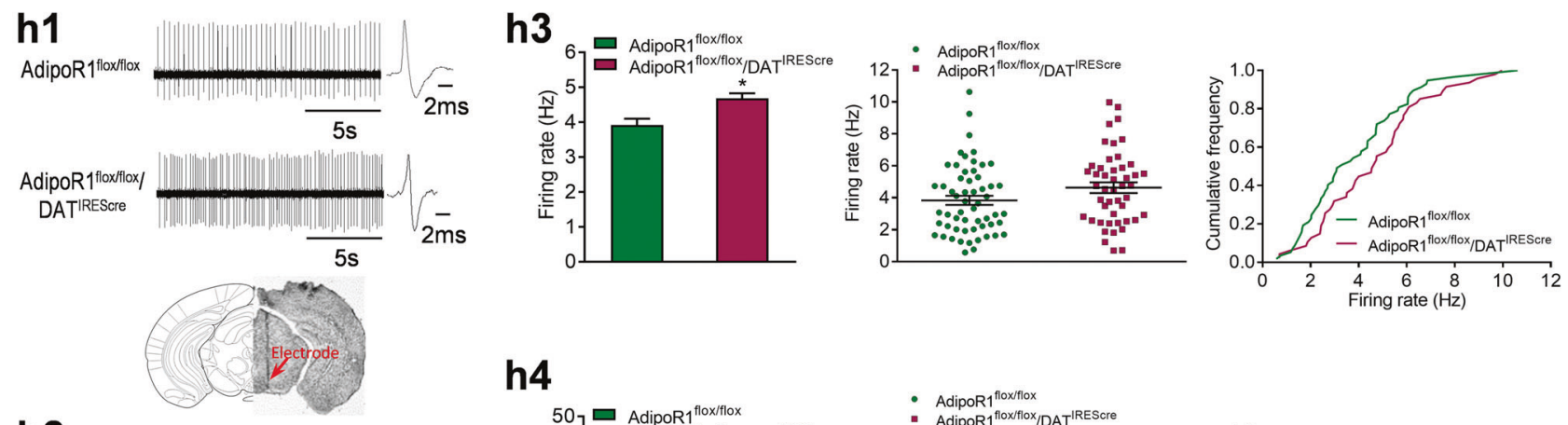

h2

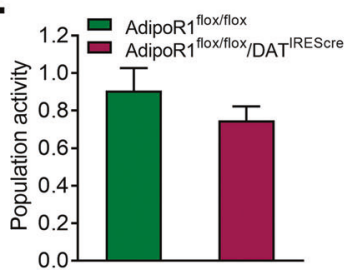

h4
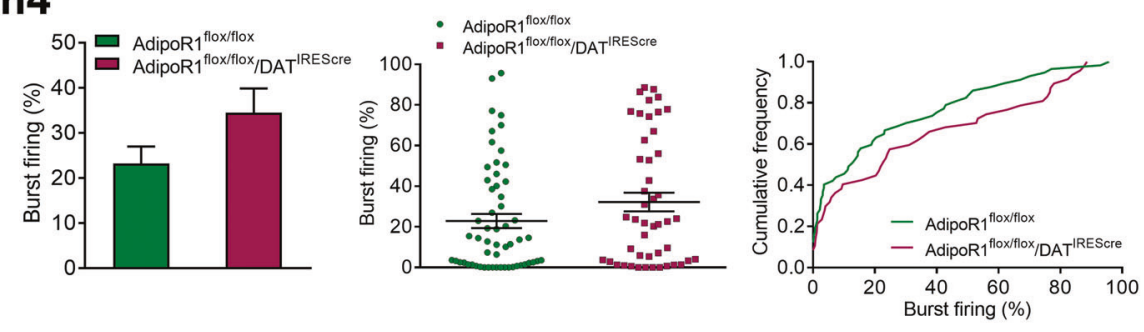

Fig. 4 (Continued)

(AdipoR1 $1^{\text {flox/flox }: ~} 3.92 \pm 0.18 \mathrm{~Hz} ; n=7$ mice, 57 neurons; AdipoR $1^{\text {flox/flox }} / \mathrm{DAT}{ }^{\text {IREScre }}: 4.68 \pm 0.14 \mathrm{~Hz} ; n=7$ mice, 47 neurons; Mann-Whitney test, $P=0.018$; Fig. 4h3) although spontaneously active DA neuron population and percentage of burst firing remained no difference (population activity: AdipoR $1^{\text {flox/flox }}: 0.91 \pm 0.12$ neurons/track; AdipoR $1^{\text {flox/flox } /}$ DAT $^{\text {IREScre }}: 0.75 \pm 0.08$ neurons/track; $t_{(12)}=1.110, P=$ 0.289 ; percent burst firing: AdipoR $1^{\text {flox/flox }}: 23.20 \pm 3.78 \%$ (50 neurons); AdipoR $1^{\text {flox/flox }} / \mathrm{DAT}$ IREScre $^{\text {I }} 34.49 \pm 5.36 \%$ (43 neurons); $t_{(12)}=1.722, \quad P=0.111$; Fig. $4 \mathrm{~h} 2$ and Fig. 4h4). These changes in dopamine neuron firing activity are in line with the anxiety-like behavioral phenotype of AdipoR $1^{\text {flox/flox }} / \mathrm{DAT}{ }^{\mathrm{IRES} \text { cre }}$ mice.

\section{AdipoR1 mediates adiponectin action on VTA dopamine neuron activity}

To determine whether adiponectin action on firing properties of VTA dopamine neurons is mediated via activation of AdipoR1 on dopamine neurons, we examined the effects of intra-VTA infusion of adiponectin in AdipoR $1^{\text {flox/flox/ }}$ $D A T^{\text {IREScre }}$ mice in comparison with AdipoR $1^{\text {flox/flox }}$ littermate control mice. As observed in wild-type mice, local infusion of adiponectin $(0.15 \mu \mathrm{g}$ in $0.5 \mu \mathrm{l})$ reduced the number of spontaneously active VTA dopamine neurons (Vehicle: $1.06 \pm 0.10$ neurons/track, 57 neurons from nine mice; Adiponectin: $0.54 \pm 0.05$ neurons/track, 29 neurons 

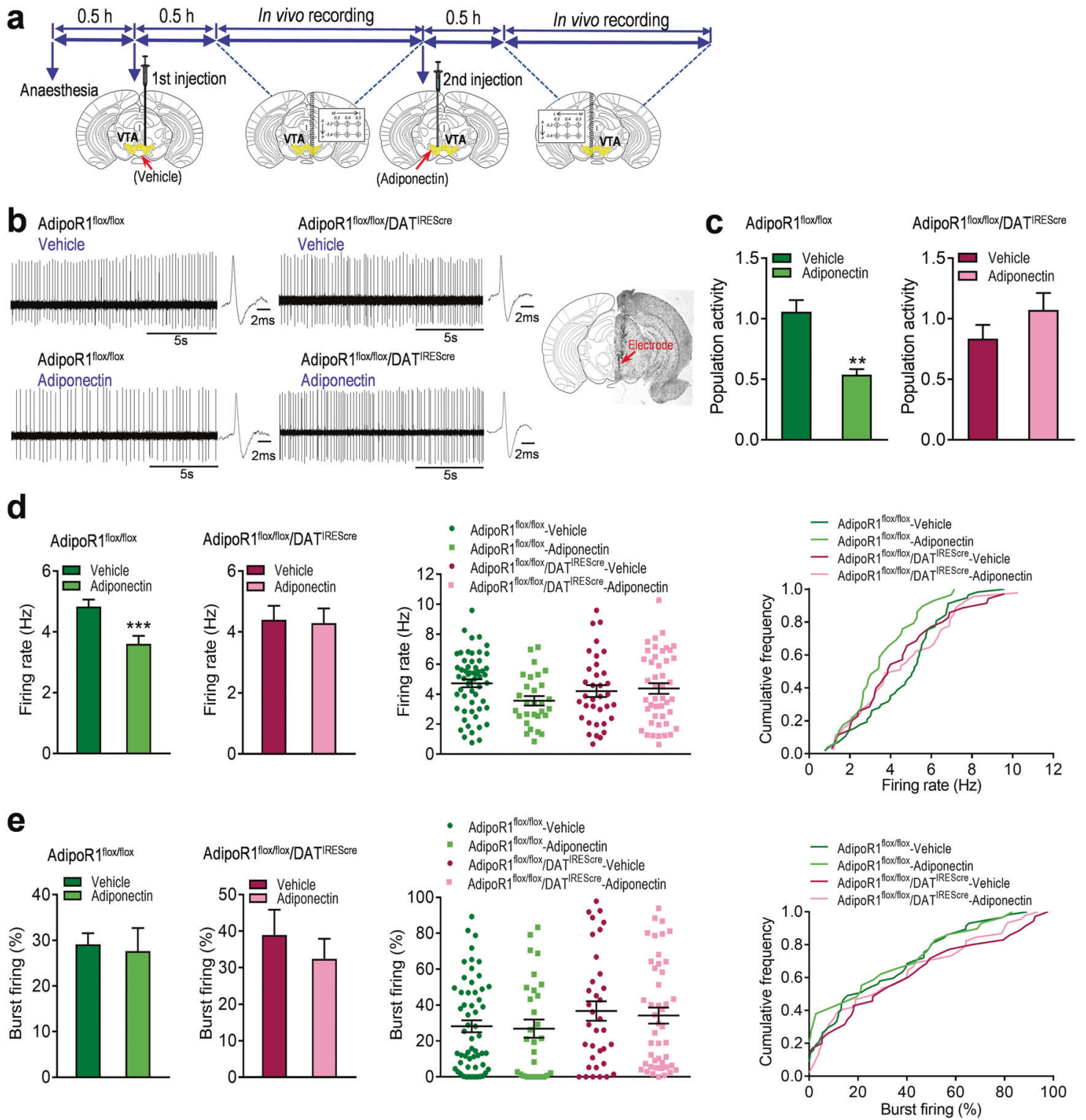

Fig. 5 AdipoR1 mediates the effects of adiponectin on VTA dopamine neuron activity and anxiety-like behavior. (a) Schematic procedure of in vivo extracellular recording of dopamine neurons in the VTA. (b) Left, representative extracellular voltage traces from VTA dopamine neurons; right, representative image demonstrating the electrode track through the VTA. (c) Number of spontaneously active dopamine neurons per track in the VTA. (d) Left and middle-left, firing rate; middle-right, scatter plot distribution; right, cumulative frequency distribution. (e) Left and middle-left, percentage of burst firing; middle-right, scatter plot distribution; right, cumulative frequency distribution. AdipoR $1^{\text {flox/flox }}+$ vehicle: $n=9$ mice, AdipoR $1^{\text {flox/flox }}+$

from nine mice; Wilcoxon signed-rank test, $P=0.008$; Fig. 5c) and firing rate (Vehicle: $4.84 \pm 0.23 \mathrm{~Hz}$; Adiponectin: $3.61 \pm 0.26 \mathrm{~Hz} ; t_{(8)}=14.50, P<0.0001$; Fig. $\left.5 \mathrm{~d}\right)$ in AdipoR $1^{\text {flox/flox }}$ mice. However, these effects of adiponectin in the VTA were abolished in AdipoR $1^{\text {flox/flox}} / \mathrm{DAT} \mathrm{T}^{\mathrm{IRES}} \mathrm{ere}$ mice (population activity: Vehicle: $0.83 \pm 0.11,35$ neurons adiponectin: $n=9$ mice, AdipoR $1^{\text {flox/llox}} / \mathrm{DAT}^{\mathrm{IRES}}$ +re + vehicle: $n=7$ mice; AdipoR $1^{\text {flox/flox }} / \mathrm{DAT}{ }^{\mathrm{IRES} c r e}+$ Adiponectin: $n=7$ mice. (f) Representative traces of the elevated plus maze test in four different treatment groups. (g) Top, percentage of open/total arm time; bottom, percentage of open/total arm entries. (h) Top, representative picture showing injection sites; bottom, schematic diagram of injection sites in the VTA. AdipoR $1^{\text {flox/flox }}+$ vehicle: $n=7$ mice; AdipoR $1^{\text {flox/flox }}+$ adiponectin: $n=6$ mice; AdipoR $1^{\text {flox/flox}} / \mathrm{DAT}^{\mathrm{IRES}}{ }^{\mathrm{R} e}+$ vehicle: $n=6$ mice; AdipoR $1^{\text {flox/flox } / D A T}{ }^{\text {IREScre }}+$ Adiponectin: $n=7$ mice. $* * P<$ $0.01, * * * P<0.001$ compared with the vehicle-treated mice

from seven mice; Adiponectin: $1.07 \pm 0.14$ neurons/track, 45 neurons from seven mice; $t_{(6)}=1.876, P=0.110$; firing rate: Vehicle: $4.40 \pm 0.46 \mathrm{~Hz}$; Adiponectin: $4.29 \mathrm{f} 0.49 \mathrm{~Hz}$; $t_{(6)}=0.148, P=0.888$; Fig. 5c, d), suggesting that adiponectin acts directly on dopamine neurons via AdipoR1 to inhibit VTA dopamine neuron activity. 

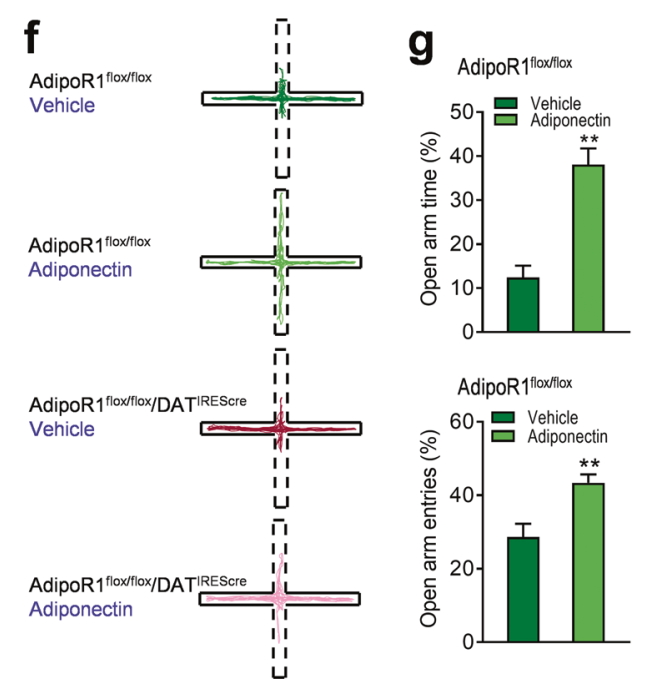

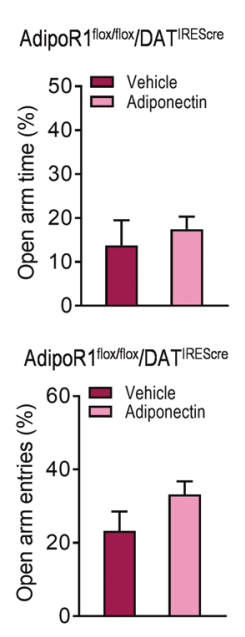

h
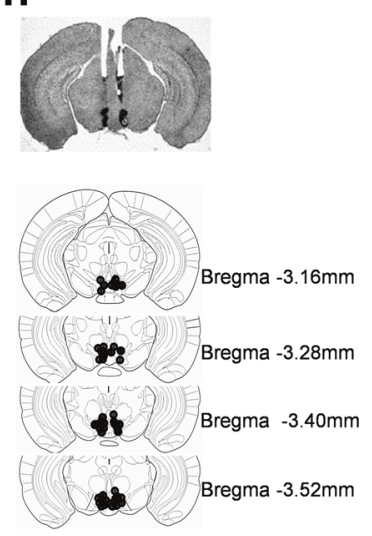

Fig. 5 (Continued)

\section{AdipoR1 in dopamine neurons mediates VTA adiponectin action on anxiety-like behavior}

To determine if VTA adiponectin action on anxiety-like behavior is mediated via activation of AdipoR1 on dopamine neurons, we assessed the behavioral effects of bilateral intra-VTA infusion of adiponectin in AdipoR $1^{\text {flox/flox/ }}$ $D A T^{\mathrm{IRES} c r e}$ mice vs. AdipoR $1^{\text {flox/flox }}$ control mice in the elevated plus maze test. Intra-VTA infusion of adiponectin $(0.15 \mu \mathrm{g} / \mathrm{side})$ in AdipoR $1^{\text {flox/flox }}$ control mice significantly reduced the percentage of open/total arm time and entries (open/total arm time: Mann-Whitney test, $P=0.001$; open/ total arm entries: $t_{(11)}=3.317, P=0.007$; Fig. $5 \mathrm{~g}$ ). However, the effects of intra-VTA adiponectin injection in the elevated plus maze were abolished in AdipoR $1^{\text {flox/flox/ }}$ DAT $^{\text {IREScre }}$ mice (open/total arm time: $t_{(11)}=0.602, P=$ 0.560 ; open/total arm entries: $t_{(11)}=1.604, P=0.137$; Fig. 5g). These findings suggest that adiponectin acts directly on dopamine neurons to modulate anxiety-related behavior through AdipoR1 activation.

\section{Discussion}

The results of the present study demonstrate that the adipocyte-derived hormone adiponectin can directly modulate the activity of VTA dopamine neurons and anxietyrelated behavior. Our data show that adiponectin suppresses spontaneous firing activity of VTA dopamine neurons and reduces anxiety-like behavior, whereas adiponectin haploinsufficiency produces the opposite effects. Moreover, acute stress-induced activation of VTA dopamine neurons and anxiogenic response can be dampened by intraVTA infusion of adiponectin and enhanced by targeted deletion of AdipoR1 in dopamine neurons. Further investigation revealed that AdipoR1 on dopamine neurons is required for adiponectin action on spontaneous neuronal activity and anxiety-like behavior. This is the first study to show that VTA dopamine neurons are direct targets for the action of adiponectin and mediate its effects on anxietyrelated behavior, offering an explanation of the association between metabolic disorders and anxiety.

It has become well recognized that dopamine neurons in the VTA transmit not only reward signals but also signals related to aversive, stressful events [3-8]. VTA dopamine neurons exhibit heterogeneous responses to aversive stimuli $[6,7]$. Stressful stimuli can either inhibit or activate dopamine neurons, depending on stress type, duration and intensity [3-7] and leading to different behavioral consequences $[4,40,41]$. These findings suggest that VTA dopamine neurons are organized into distinct functional ensembles and govern different behavioral responses. Acute restraint stress has been consistently shown to induce a pronounced activation of VTA dopamine neurons and cause anxiogenic behavior [5, 7, 40, 41]. In this study, we observed that, under basal conditions, intra-VTA infusion of adiponectin or the adiponectin mimetic AdipoRon inhibits the spontaneous activity of VTA dopamine neurons manifested as a decrease in dopamine neuron population activity and firing rate. As reported previously in rats [7, 44], we found that acute restraint stress increases dopamine neuron population activity in mice; and this effect of stress can be reversed by intra-VTA injection of AdipoRon. Behaviorally, ICV infusion of adiponectin induces anxiolytic effects in the elevated plus maze and light-dark box tests. Direct infusion of adipoRon into the VTA attenuates the restraint stressinduced anxiogenic response. These observations indicate that activation of adiponectin receptors in the VTA are sufficient to counteract the effects of stress on dopamine neuronal activity and associated anxiety behavior. 
Given the reversal of the stress effects by administration of adiponectin, we asked whether an adiponectin insufficiency status would cause stress-like effects on neuronal activity and anxiety behavior. Consistent with previous reports [29, 32, 42], the heterozygous adiponectin knockout $\left(\right.$ Adipo $^{+/}$) mice have $~ 60 \%$ reduction in plasma adiponectin levels, representing a condition of insufficiency. Using this model, we were able to explore the relationships between adiponectin insufficiency, VTA dopamine neuron activity and anxiety behavior. Low adiponectin levels in Adipo ${ }^{+/-}$ mice led to increased firing rate of VTA dopamine neurons without a significant effect on the number of spontaneously active dopamine neurons, which differs from the effects of restraint stress exposure. This suggests that adiponectin insufficiency and restraint stress influence different firing properties of VTA dopamine neurons. However, similar to stress exposure, adiponectin insufficiency causes anxiogenic-like effects. Interestingly, increased anxiety was not observed among mice with a homozygous deletion $\left(\right.$ Adipo $\left.^{-/}\right)$in the adiponectin gene $[31,33]$. Although this non-monotonic gene dosage-behavioral phenotype relationship is at first surprising, a similar pattern of genotype/ phenotype interaction has been reported in mice deficient for catechol-O-methyltransferase (COMT) and $\alpha$-calciumcalmodulin kinase II $[45,46]$. While we cannot completely rule out the possibility that background genes may influence this genotype-phenotype non-monotonic association, one explanation could be that compensatory mechanisms are triggered by the absence of adiponectin but not by reduced adiponectin levels. It is possible that $42 \%$ normal adiponectin levels in Adipo ${ }^{+/-}$mice are below the threshold for the induction of compensatory changes. However, genetic compensation for total absence of adiponectin appears to occur for specific behavioral processes. We have recently shown that mice lacking adiponectin display impaired fear extinction [31]. Another explanation is that anxiety behavior may be differentially regulated by AdipoR1 and AdipoR2. These two receptor subtypes have distinct expression patterns in the brain and different binding affinity for adiponectin $[28,29]$. AdipoR1 has relatively lower affinity for full-length adiponectin, the vast majority form [28]. In situ hybridization revealed abundant expression of AdipoR1 in the VTA, whereas AdipoR2 mRNA was almost undetectable in this region. Quantitative mRNA expression analysis by real-time PCR showed levels of AdipoR1 and AdipoR2 mRNA in the VTA were not altered in Adipo $^{+/}$mice compared to wild-type littermate controls (data not shown). Thus, we speculate that a reduction in endogenous adiponectin concentrations in $\mathrm{Adipo}^{+/-}$mice would cause a preferential loss of low-affinity binding sites, i.e. AdipoR 1 receptor binding, which might be responsible for the anxiogenic behavior. In support of this notion, AAV-Cremediated deletion of AdipoR1 in the VTA of adult mice increases anxiety, implicating dysfunction of VTA adiponectin/AdipoR1 signaling as a possible mechanism underlying anxiety-like behavior.

The physiological importance of AdipoR1 in dopamine neurons in modulating anxiety-like behavior and neuronal activity was confirmed using a conditional knockout mouse model, in which AdipoR1 was deleted specifically in dopamine neurons. Loss of AdipoR1 in dopamine neurons markedly enhanced behavioral and neuronal responses to restraint stress, suggesting that defective AdipoR1 signaling in dopamine neurons promotes susceptibility to stress. Moreover, we found that the inhibitory effects of intra-VTA injection of adiponectin on dopamine neuron population activity and firing rate were abolished in mice lacking AdipoR1 in dopamine neurons. Consistent with the electrophysiological findings, the anxiolytic effect of adiponectin was also abolished by conditional deletion of AdipoR1 in dopamine neurons. These observations suggest that AdipoR1 in dopamine neurons is essential for adiponectin action on the firing activity of these neurons and anxiety-related behavior, and that targeting VTA dopamine neurons via AdipoR1 is likely to be an underlying mechanism by which adiponectin influences anxiety behavior.

Anxiety symptoms are particularly common in those individuals with metabolic disorders [47]. It is well known that levels of adiponectin are low in people with obesity and type 2 diabetic subjects $[18,48,49]$. This study provided the first evidence that adiponectin directly target midbrain dopamine neurons, and low activation of AdipoR1 on these neurons contributes to anxiogenic behavior. Our results, in combination with previous findings $[14,15]$, suggest that the VTA is an important neural substrate of stress susceptibility and anxiety-related behavior that is sensitive to adipocyte hormonal signals.

Acknowledgements This work was supported by NIH grants MH076929, MH100583, and MH096251 (X-YL).

Author contributions FS, YL, JY, CL, LS, JG, DZ, and MG conducted the studies. FS and YL performed the data analysis and prepared the figures. DL provided expert knowledge and advice on in vivo electrophysiology, data collection, and analysis. PES provided adiponectin knockout mice. X-YL conceived the study, designed the experiments, and wrote the manuscript with the input from all authors.

\section{Compliance with ethical standards}

Conflict of interest The authors declare that they have no conflict of interest.

Open Access This article is licensed under a Creative Commons Attribution 4.0 International License, which permits use, sharing, adaptation, distribution and reproduction in any medium or format, as long as you give appropriate credit to the original author(s) and the source, provide a link to the Creative Commons license, and indicate if 
changes were made. The images or other third party material in this article are included in the article's Creative Commons license, unless indicated otherwise in a credit line to the material. If material is not included in the article's Creative Commons license and your intended use is not permitted by statutory regulation or exceeds the permitted use, you will need to obtain permission directly from the copyright holder. To view a copy of this license, visit http://creativecommons. org/licenses/by/4.0/.

\section{References}

1. Nestler EJ, Carlezon WA Jr. The mesolimbic dopamine reward circuit in depression. Biol Psychiatry. 2006;59:1151-9.

2. Coque L, Mukherjee S, Cao JL, Spencer S, Marvin M, Falcon E, et al. Specific role of VTA dopamine neuronal firing rates and morphology in the reversal of anxiety-related, but not depressionrelated behavior in the ClockDelta19 mouse model of mania. Neuropsychopharmacology. 2011;36:1478-88.

3. Chaudhury D, Walsh JJ, Friedman AK, Juarez B, Ku SM, Koo $\mathrm{JW}$, et al. Rapid regulation of depression-related behaviours by control of midbrain dopamine neurons. Nature. 2013;493:532-6.

4. Tye KM, Mirzabekov JJ, Warden MR, Ferenczi EA, Tsai HC, Finkelstein J, et al. Dopamine neurons modulate neural encoding and expression of depression-related behaviour. Nature. 2013;493:537-41.

5. Anstrom KK, Woodward DJ. Restraint increases dopaminergic burst firing in awake rats. Neuropsychopharmacology. 2005;30:1832-40.

6. Brischoux F, Chakraborty S, Brierley DI, Ungless MA. Phasic excitation of dopamine neurons in ventral VTA by noxious stimuli. Proc Natl Acad Sci USA. 2009;106:4894-9.

7. Valenti O, Gill KM, Grace AA. Different stressors produce excitation or inhibition of mesolimbic dopamine neuron activity: response alteration by stress pre-exposure. Eur J Neurosci. 2012;35:1312-21.

8. Ungless MA, Magill PJ, Bolam JP. Uniform inhibition of dopamine neurons in the ventral tegmental area by aversive stimuli. Science. 2004;303:2040-2.

9. Abizaid A, Liu ZW, Andrews ZB, Shanabrough M, Borok E, Elsworth JD, et al. Ghrelin modulates the activity and synaptic input organization of midbrain dopamine neurons while promoting appetite. J Clin Invest. 2006;116:3229-39.

10. Hommel JD, Trinko R, Sears RM, Georgescu D, Liu ZW, Gao $\mathrm{XB}$, et al. Leptin receptor signaling in midbrain dopamine neurons regulates feeding. Neuron. 2006;51:801-10.

11. Labouebe G, Liu S, Dias C, Zou H, Wong JC, Karunakaran S, et al. Insulin induces long-term depression of ventral tegmental area dopamine neurons via endocannabinoids. Nat Neurosci. 2013;16:300-8.

12. Tang F, Wang G, Lian Y. Association between anxiety and metabolic syndrome: a systematic review and meta-analysis of epidemiological studies. Psychoneuroendocrinology. 2017;77:112-21.

13. Hiles SA, Revesz D, Lamers F, Giltay E, Penninx BW. Bidirectional prospective associations of metabolic syndrome components with depression, anxiety, and antidepressant use. Depress Anxiety. 2016;33:754-64.

14. Liu J, Perez SM, Zhang W, Lodge DJ, Lu XY. Selective deletion of the leptin receptor in dopamine neurons produces anxiogeniclike behavior and increases dopaminergic activity in amygdala. Mol Psychiatry. 2011;16:1024-38.

15. Liu J, Guo M, Lu XY. Leptin/LepRb in the ventral tegmental area mediates anxiety-related behaviors. Int J Neuropsychopharmacology. 2015;19:pyv115.

16. Maeda K, Okubo K, Shimomura I, Funahashi T, Matsuzawa Y, Matsubara K. cDNA cloning and expression of a novel adipose specific collagen-like factor, apM1 (AdiPose Most abundant Gene transcript 1). Biochem Biophys Res Commun. 1996;221:286-9.

17. Scherer PE, Williams S, Fogliano M, Baldini G, Lodish HF. A novel serum protein similar to $\mathrm{C} 1 \mathrm{q}$, produced exclusively in adipocytes. J Biol Chem. 1995;270:26746-9.

18. Arita Y, Kihara S, Ouchi N, Takahashi M, Maeda K, Miyagawa J, et al. Paradoxical decrease of an adipose-specific protein, adiponectin, in obesity. Biochem Biophys Res Commun. 1999;257:79-83.

19. Hamilton MP, Gore MO, Ayers CR, Xinyu W, McGuire DK, Scherer PE. Adiponectin and cardiovascular risk profile in patients with type 2 diabetes mellitus: parameters associated with adiponectin complex distribution. Diab Vasc Dis Res. 2011;8:190-4.

20. De Rosa A, Monaco ML, Capasso M, Forestieri P, Pilone V, Nardelli C, et al. Adiponectin oligomers as potential indicators of adipose tissue improvement in obese subjects. Eur J Endocrinol. 2013;169:37-43.

21. Kaser S, Tatarczyk T, Stadlmayr A, Ciardi C, Ress C, Tschoner A, et al. Effect of obesity and insulin sensitivity on adiponectin isoform distribution. Eur J Clin Invest. 2008;38:827-34.

22. Kadowaki T, Yamauchi T. Adiponectin and adiponectin receptors. Endocr Rev. 2005;26:439-51.

23. Wang ZV, Scherer PE. Adiponectin, the past two decades. J Mol Cell Biol. 2016;8:93-100.

24. Yamauchi T, Iwabu M, Okada-Iwabu M, Kadowaki T. Adiponectin receptors: a review of their structure, function and how they work. Best Pract Res Clin Endocrinol Metab. 2014;28:15-23.

25. Kubota N, Yano W, Kubota T, Yamauchi T, Itoh S, Kumagai H, et al. Adiponectin stimulates AMP-activated protein kinase in the hypothalamus and increases food intake. Cell Metab. 2007;6:55-68.

26. Neumeier M, Weigert J, Buettner R, Wanninger J, Schaffler A, Muller AM, et al. Detection of adiponectin in cerebrospinal fluid in humans. Am J Physiol Endocrinol Metab. 2007;293:E965-969.

27. Kusminski CM, McTernan PG, Schraw T, Kos K, O'Hare JP, Ahima R, et al. Adiponectin complexes in human cerebrospinal fluid: distinct complex distribution from serum. Diabetologia. 2007;50:634-42.

28. Yamauchi T, Kamon J, Ito Y, Tsuchida A, Yokomizo T, Kita S, et al. Cloning of adiponectin receptors that mediate antidiabetic metabolic effects. Nature. 2003;423:762-9.

29. Liu J, Guo M, Zhang D, Cheng SY, Liu M, Ding J, et al. Adiponectin is critical in determining susceptibility to depressive behaviors and has antidepressant-like activity. Proc Natl Acad Sci USA. 2012;109:12248-53.

30. Yamauchi T, Nio Y, Maki T, Kobayashi M, Takazawa T, Iwabu $\mathrm{M}$, et al. Targeted disruption of AdipoR1 and AdipoR2 causes abrogation of adiponectin binding and metabolic actions. Nat Med. 2007;13:332-9.

31. Zhang D, Wang X, Wang B, Garza JC, Fang X, Wang J, et al. Adiponectin regulates contextual fear extinction and intrinsic excitability of dentate gyrus granule neurons through AdipoR2 receptors. Mol Psychiatry. 2017;22:1044-55.

32. Nawrocki AR, Rajala MW, Tomas E, Pajvani UB, Saha AK, Trumbauer ME, et al. Mice lacking adiponectin show decreased hepatic insulin sensitivity and reduced responsiveness to peroxisome proliferator-activated receptor gamma agonists. J Biol Chem. 2006;281:2654-60.

33. Guo M, Li C, Lei Y, Xu S, Zhao D, Lu XY. Role of the adipose PPARgamma-adiponectin axis in susceptibility to stress and depression/anxiety-related behaviors. Mol Psychiatry. 2017;22:1056-68.

34. Guo M, Lu Y, Garza JC, Li Y, Chua SC, Zhang W, et al. Forebrain glutamatergic neurons mediate leptin action on depressionlike behaviors and synaptic depression. Transl Psychiatry. 2012;2: e83. 
35. Guo M, Huang TY, Garza JC, Chua SC, Lu XY. Selective deletion of leptin receptors in adult hippocampus induces depressionrelated behaviours. Int J Neuropsychopharmacol. 2013;16:857-67.

36. Rodgers RJ, Dalvi A. Anxiety, defence and the elevated plusmaze. Neurosci Biobehav Rev. 1997;21:801-10.

37. Ungless MA, Grace AA. Are you or aren't you? Challenges associated with physiologically identifying dopamine neurons. Trends Neurosci. 2012;35:422-30.

38. Grace AA, Bunney BS. Intracellular and extracellular electrophysiology of nigral dopaminergic neurons--1. Identification and characterization. Neuroscience. 1983;10:301-15.

39. Okada-Iwabu M, Yamauchi T, Iwabu M, Honma T, Hamagami K, Matsuda K, et al. A small-molecule AdipoR agonist for type 2 diabetes and short life in obesity. Nature. 2013;503:493-9.

40. Liu J, Garza JC, Li W, Lu XY. Melanocortin-4 receptor in the medial amygdala regulates emotional stress-induced anxiety-like behaviour, anorexia and corticosterone secretion. Int $\mathrm{J}$ Neuropsychopharmacol. 2013;16:105-20.

41. Liu J, Garza JC, Truong HV, Henschel J, Zhang W, Lu XY. The melanocortinergic pathway is rapidly recruited by emotional stress and contributes to stress-induced anorexia and anxiety-like behavior. Endocrinology. 2007;148:5531-40.

42. Kubota N, Terauchi Y, Yamauchi T, Kubota T, Moroi M, Matsui $\mathrm{J}$, et al. Disruption of adiponectin causes insulin resistance and neointimal formation. J Biol Chem. 2002;277:25863-6.
43. Backman CM, Malik N, Zhang Y, Shan L, Grinberg A, Hoffer BJ, et al. Characterization of a mouse strain expressing Cre recombinase from the 3' untranslated region of the dopamine transporter locus. Genesis. 2006;44:383-90.

44. Valenti O, Lodge DJ, Grace AA. Aversive stimuli alter ventral tegmental area dopamine neuron activity via a common action in the ventral hippocampus. J Neurosci. 2011;31:4280-9.

45. Chen C, Rainnie DG, Greene RW, Tonegawa S. Abnormal fear response and aggressive behavior in mutant mice deficient for alpha-calcium-calmodulin kinase II. Science. 1994;266:291-4.

46. Gogos JA, Morgan M, Luine V, Santha M, Ogawa S, Pfaff D, et al. Catechol-O-methyltransferase-deficient mice exhibit sexually dimorphic changes in catecholamine levels and behavior. Proc Natl Acad Sci USA. 1998;95:9991-6.

47. Kahl KG, Schweiger U, Correll C, Muller C, Busch ML, Bauer $\mathrm{M}$, et al. Depression, anxiety disorders, and metabolic syndrome in a population at risk for type 2 diabetes mellitus. Brain Behav. 2015;5:e0306.

48. Hotta K, Funahashi T, Arita Y, Takahashi M, Matsuda M, Okamoto Y, et al. Plasma concentrations of a novel, adipose-specific protein, adiponectin, in type 2 diabetic patients. Arterioscler Thromb Vasc Biol. 2000;20:1595-9.

49. Turer AT, Khera A, Ayers CR, Turer CB, Grundy SM, Vega GL, et al. Adipose tissue mass and location affect circulating adiponectin levels. Diabetologia. 2011;54:2515-24. 